\title{
COMPOSTO DE MARKETING EM REDES DE COMPRAS: ESTUDO COMPARATIVO DAS PERCEPÇÕES DE ADMINISTRADORES E ASSOCIADOS EM UMA REDE DE SUPERMERCADOS
}

\author{
Douglas Heinz \\ dh@unidavi.edu.br \\ Centro Universitário para o Desenvolvimento do Alto Vale do Itajaí - Rio do Sul, SC / Brasil
}

Jane Iara Pereira da Costa

costapjane@uol.com.br

Universidade do Estado de Santa Catarina - Florianópolis, SC / Brasil

Erick William Pereira

erick@wpcom.com.br

Centro Universitário para o Desenvolvimento do Alto Vale do Itajaí - Rio do Sul, SC / Brasil

http://dx.doi.org/10.1590/1413-2311062201238437

Recebido em 05/10/2012

Aprovado em 24/09/2013

Disponibilizado em 01/08/2014

Avaliado pelo sistema double blind review

Revista Eletrônica de Administração

Editor: Luís Felipe Nascimento

ISSN 1413-2311 (versão on-line)

Editada pela Escola de Administração da Universidade Federal do Rio Grande do Sul.

Periodicidade: Quadrimestral

Sistema requerido: Adobe Acrobat Reader.

\section{RESUMO}

A formação de redes de compras é uma estratégia cada vez mais utilizada por pequenos varejistas. Este formato causa impactos na administração das empresas participantes, que passam atuar em um contexto coletivo onde decisões são tomadas com base em interesses de um grupo, e não mais observando apenas necessidades individuais. Uma das áreas fortemente afetadas neste contexto é o marketing, já que os associados tendem a delegar à rede parte da responsabilidade por suas ações mercadológicas. Este trabalho analisou os impactos de tal situação sobre os tradicionais elementos do composto de marketing: produto, preço, comunicação e distribuição. Realizou-se um estudo de caso em uma rede de compras formada por pequenos supermercadistas, comparando as percepções dos administradores e dos associados sobre o tema. Inicialmente ocorreu uma pesquisa qualitativa através de entrevista com roteiro semiestruturado com os administradores, com posterior análise de discurso com categorização. Em seguida os associados responderam à pesquisa quantitativa por meio de questionário, onde os dados foram analisados através dos cálculos de correlação e do coeficiente de determinação, além da distribuição de frequências. Os resultados obtidos indicam haver uma correlação positiva entre a utilização da rede e o nível de satisfação dos associados, além de evidenciar que o composto de marketing dos varejistas participantes foi REAd | Porto Alegre - Edição 78 - Nº 2 - maio/agosto 2014 - p. 529-570 
Composto de marketing em redes de compras: estudo comparativo das percepções de administradores e associados em uma rede de supermercados

fortemente impactado pelas ações da rede. Identificou-se ainda que há convergência de percepções quanto às ações de marketing desenvolvidas, consideradas adequadas e positivas para o grupo, exceto no que diz respeito à adoção de marca própria de produtos.

Palavras-chave: redes de compras; supermercados; composto de marketing.

\title{
MARKETING MIX IN A BUYING NETWORK: A COMPARATIVE STUDY OF THE PERCEPTIONS OF MANAGERS AND ASSOCIATES IN A SUPERMARKET NETWORK
}

\begin{abstract}
The formation of purchasing networks is a strategy increasingly used by small retailers. But this format has an impact on the administration of the participating companies, who are acting in a collective context, where decisions are made based on the interests of a group, and not just observing individual needs. One of the areas heavily affected in this context is marketing, as members tend to delegate to the network part of the responsibility of their marketing actions. This study examined the impact of this situation on the traditional elements of the marketing mix: product, price, communication and distribution. The case study was conducted in a purchasing network formed by small supermarkets, comparing the perceptions of managers and associates about the subject. Initially semi-structured interviews were performed with administrators, with subsequent qualitative analysis of responses by analyzing speech with categorization. Then associates managers responded to quantitative research through questionnaires, where the data were analyzed by calculating correlation and determination coefficient, and frequency distribution. The results indicated a positive correlation between the use of the network and the level of satisfaction of members, and demonstrate that the marketing mix of retailers participating was strongly impacted by the actions of the network, and that there is a convergence of perceptions as to the marketing actions developed, considered appropriate and positive for the group, except with regard to the adoption of private label products.
\end{abstract}

Keywords: purchasing networks; supermarket; marketing mix.

\section{LA MEZCLA DE MERCADOTECNIA EN CENTRALES DE COMPRAS: UN} ESTUDIO COMPARATIVO DE LAS PERCEPCIONES DE LOS DIRECTIVOS Y ASOCIADOS EN UNA RED DE SUPERMERCADOS

\section{RESUMEN}

Las Centrales de Compras son una estrategia cada vez más utilizada por los pequeños comerciantes. Este formato tiene un impacto en la administración de las empresas participantes, que se insertan en un contexto colectivo en el que las decisiones se toman en base a los intereses de un grupo, y no sólo por la observación de las necesidades individuales. Uno de los ámbitos más afectados en este contexto es la mercadotecnia. Este estudio analiza REAd | Porto Alegre - Edição 78 - N 2 - maio/agosto 2014 - p. 529-570 
Douglas Heinz, Jane Iara Pereira da Costa \& Erick William Pereira

el impacto de esta situación sobre los elementos tradicionales del marketing mix: producto, precio, comunicación y distribución. Hemos llevado a cabo un estudio de caso en una Central de Compras formada por pequeños supermercados, comparando las percepciones de los directivos y asociados sobre el tema. Inicialmente se hizo un estudio cualitativo mediante entrevista semiestructurada con la administración, con el posterior análisis del discurso con categorización. Entonces los miembros respondieron a la investigación cuantitativa mediante un cuestionario, en donde los datos se analizaron mediante el cálculo de la correlación y el coeficiente de determinación, y la frecuencia de distribución. Los resultados indican que existe una correlación positiva entre el uso de la Central y el nivel de satisfacción de los miembros, además de destacar que lo marketing mix de los minoristas participantes se vio fuertemente afectado por las acciones de la Central de Compras. También se encontró que hay convergencia de percepciones sobre las acciones de marketing desarrolladas, salvo en lo relativo a la adopción de los productos de marca propia.

Palabras clave: Centrales de Compras; Supermercados; Mezcla de Mercadotecnia.

\section{INTRODUÇÃO}

O varejo é constituído, na sua maioria, por pequenas e médias empresas, que devido ao seu porte, total dependência dos fornecedores, dificuldades no acesso ao crédito, além da pouca influência sobre a cadeia produtiva, enfrentam grandes barreiras, causadas especialmente pelos varejistas internacionais que impõem aos fabricantes condições que prejudicam o pequeno comerciante local. Assim, utilizando o exemplo de modelos de países Europeus e apoiados nas políticas de diferenciação de preços para grandes volumes de compra, os pequenos varejistas começaram a se articular formando associações ou cooperativas, com o objetivo inicial de obter benefícios decorrentes das compras de larga escala e um maior poder de barganha junto aos seus fornecedores (YEMAL; FUSCO; ROSPI, 2006; DUNKE; ANAZCO; PAUL, 2010; XAVIER FILHO et al., 2010).

A estrutura originada neste processo de associação ainda não possui uma terminologia uniforme para a sua designação (ESSIG, 2000). Muitas vezes chamadas de "centrais de compra” (GHISI; DE CARMARGO; MARTINELLI, 2003; OLIVEIRA; MACHADO, 2008), “central de negócio” (POUSA et al., 2006; DUNKE; ANAZCO; PAUL, 2010; XAVIER FILHO et al., 2010), rede de negócios (AMARAL, 2007), cooperativas de varejo (KOTLER; ARMSTRONG, 2003; LAS CASAS, 2008) ou ainda “redes de cooperação no varejo” (LIVATO; DE BENEDICTO, 2010), o fenômeno do agrupamento de empresas de pequeno porte merece observações da academia, devido à sua contribuição para a geração de empregos, para o aperfeiçoamento da logística e para a crescente expansão do setor varejista (BONASSI; LISBOA, 2003, POUSA et al., 2006). Além disso, essa forma de encarar o REAd | Porto Alegre - Edição 78 - Nº 2 - maio/agosto 2014 - p. 529-570 
Composto de marketing em redes de compras: estudo comparativo das percepções de administradores e associados em uma rede de supermercados

posicionamento das empresas transforma a tradicional visão puramente competitiva das relações organizacionais, exigindo a análise em um novo contexto, mais abrangente, holístico, sistêmico, flexível e complementar (XAVIER FILHO et al., 2010). Logo, o fenômeno das redes de compras merece ser analisado contemplando a multiplicidade de atores envolvidos.

Wegner e Padula (2010) apontam três conjuntos de práticas em redes organizacionais que têm recebido atenção acadêmica: a seleção e regulação dos membros; o planejamento, comunicação e avaliação das estratégias; e a motivação dos membros para o aprendizado, a troca de informações e conhecimento e a geração de inovações. O presente trabalho insere-se no grupo de planejamento, comunicação e avaliação das estratégias.

Ao aderir ao formato de compras conjuntas, pequenos varejistas passam a delegar à rede parte de suas ações de marketing, como a seleção de produtos, a formação de preços e a comunicação. A atuação em rede exige, ainda, a constituição de uma organização administrativa particular, que realiza funções executivas em nome dos associados. Surgem então diferentes grupos de interesse, dentre os quais se destacam os administradores, que podem ser os próprios sócios ou profissionais contratados, e os associados. Este estudo compara as percepções destes dois grupos quanto às ações de marketing de uma rede, mais especificamente em relação às políticas adotadas sobre os elementos tradicionais do composto de marketing: produto, preço, promoção e distribuição.

Além desta introdução, o conteúdo do estudo compreende, na sequência, uma revisão da literatura sobre redes de compras, composto de marketing e varejo supermercadista. Posteriormente apresentam-se os procedimentos metodológicos adotados, partindo então para a análise dos resultados obtidos no trabalho. Finaliza-se com as conclusões do estudo.

\section{REDES DE COMPRAS}

Estudos sobre relações interorganizacionais têm avançado significativamente nas últimas décadas, sendo o tema objeto de debate permanente e crescente no meio acadêmico (WEGNER; PADULA, 2010; BALESTRIN; VERSCHOORE; REYES JUNIOR, 2010, GIGLIO, ONUSIC, 2013). A literatura existente sobre o assunto é extensa, indo desde redes organizacionais até redes sociais, abrangendo diversas áreas de conhecimento e perpassando várias disciplinas, o que tem gerado considerável progresso no entendimento sobre como estas redes estão estruturadas, como operam e se desenvolvem (NOHRIA, 1992; GRANDORI; SODA, 1995; PROVAN; FISH; SYDOW, 2007). 


\section{Douglas Heinz, Jane Iara Pereira da Costa \& Erick William Pereira}

No âmbito organizacional, lembram Provan, Fish e Sydow (2007), o termo rede (network) não é sempre utilizado, havendo outras designações como parcerias, alianças estratégicas, relações interorganizacionais, coalizões, arranjos cooperativos ou acordos colaborativos. Para Gulati (1998), os acordos cooperativos entre empresas são uma forma de aliança estratégica que envolve a troca, compartilhamento e desenvolvimento conjunto de produtos e/ou serviços, podendo incluir contribuições de capital, tecnologia ou outros recursos e capacidades. Brass et al. (2004, p.795) definem rede como "um conjunto de nós e o conjunto de laços que representam algum tipo de relação, ou falta de relação, entre os nós”. Os nós, segundos estes autores, referem-se aos atores envolvidos, como as pessoas ou as organizações. Já para Rolo (2001, p. 22), as redes de cooperação são “[...] a atividade ou conjunto de atividades desenvolvidas por um conjunto de intervenientes onde determinados recursos são partilhados com vista à otimização dos resultados e com retornos positivos para todos os intervenientes”.

O surgimento de novas formas organizacionais, para Lewin, Long e Carroll (1999), é decorrente de um processo de coevolução desencadeado por mudanças ambientais que fazem surgir, da população atual, novos modelos de organização. Neste sentido, as transformações no ambiente de negócios permitem explicar a expansão das redes e o consequente posicionamento do tema no centro da discussão organizacional. Bertolini (2006) ainda argumenta que as organizações em rede surgiram como resposta a desafios do ambiente empresarial, entre os quais o dilema escala versus flexibilidade, a necessidade de inovação e de redução de custos e o estímulo à postura empreendedora. Teoricamente, afirma Oliveira (2013), as redes permitem aos seus membros a mesma aprendizagem e acesso aos recursos, evitando assimetrias que poderiam ser entendidas pelos participantes como negativas.

Para Baily et al. (2000), dentre os objetivos perseguidos na área de compras incluemse o suprimento da organização de forma contínua com os produtos necessários, a compra eficiente e ética que permita a melhor utilização do capital investido e a manutenção de relacionamentos internos sólidos aliada a políticas e procedimentos adequados de compras. Diferentes estratégias podem ser desenvolvidas visando atender a estes objetivos. Uma delas é a constituição de redes horizontais denominadas centrais de compras, permitindo, segundo Cervi, Razzolini Filho e Rodrigues (2004) e Soares et. al (2011), que um grupo de comerciantes ou de indústrias efetue compras de mercadorias ou matérias-primas em maior volume, aumentando o poder de barganha e conseguindo melhores preços e condições de pagamentos nas negociações com fornecedores. Essig (2000) aponta que os primeiros estudos

REAd | Porto Alegre - Edição 78 - N 2 - maio/agosto 2014 - p. 529-570 
Composto de marketing em redes de compras: estudo comparativo das percepções de administradores e associados em uma rede de supermercados

sobre consórcios de compras foram realizados por Mitchell (1927) ${ }^{1}$ e Gushée e Boffey $(1928)^{2}$.

A criação de uma central de compras, para Olave e Amato Neto (2001), mantém a individualidade da empresa, por representar um modo de associação por afinidade de natureza informal que deixa cada empresa responsável pelo seu próprio desenvolvimento. Essig (2000) ainda argumenta que a utilização de uma rede de compras também permite reduzir os custos de transação através da redução das operações necessárias, enquanto Giglio e Onusic (2013), defendem este modelo como um caminho estratégico, visando o aumento da competitividade e a sobrevivência organizacional.

Por outro lado, Cervi, Razozzolini Filho e Rodriguez (2004) comentam que a participação em uma central de compras exige dos associados espírito coletivo, pois se trabalha com um bem comum, pensamento este corroborado por Marchi, Cassanego Junior e Wittmann (2012) que afirmam ser necessário aos gestores e associados de uma rede, no contexto competitivo atual, buscar com esta estratégia não somente a economia de custos, mas também a troca de experiências e um aprendizado coletivo que possa ser levado para as empresas.

Em seu limite, a gestão de uma rede leva os participantes a atingir os objetivos propostos pelas organizações integrantes, influenciando positivamente a competitividade de seus membros (ROTH et. al, 2012). Não obstante, algumas dificuldades também estão presentes neste modelo. O quadro 1 apresenta uma compilação de benefícios e problemas que os participantes poderão encontrar em um arranjo cooperativo de compras.

Quadro 1 - Benefícios e problemas da participação em redes de compras

\begin{tabular}{|l|cl|l|}
\hline ITEM & PONTOS PRINCIPAIS & AUTORES \\
\hline Benefícios para & $\bullet$ & Maior poder de negociação & Cavalcante (2004); Kotler \\
os participantes & $\bullet$ & Combinação de know how entre empresas & (2005); Dos Reis (2009); \\
& $\bullet$ & Armazenagem conjunta & Morosky (2010); Cervi, \\
& $\bullet$ & Rarketing compartilhado & Rodriguez (2004); Pousa et \\
& $\bullet$ & Redução de preços & al (2006); Saab, Gimenez, \\
& $\bullet$ & Rateio de despesas & Ribeiro (2000), Essig \\
& $\bullet$ & Reconhecimento de marca & (2000), Xavier Filho et al. \\
& $\bullet$ & Melhoria na logística & (2010). \\
& $\bullet$ & Aprimoramento da estratégia & \\
& $\bullet$ & Competitividade & \\
& $\bullet$ & Melhoria dos serviços aos clientes & \\
& $\bullet$ & Especialização do comprador & \\
& $\bullet$ & Acesso a fornecedores & \\
& & Redução no número de operações &
\end{tabular}

\footnotetext{
${ }^{1}$ Mitchell, W.N., 1927. Purchasing. New York, 1927

${ }^{2}$ Gusheée, E.T., Boffey, L.F., Scientific Purchasing. New York: McGraw-Hill, 1928

REAd | Porto Alegre - Edição 78 - N 2 - maio/agosto 2014 - p. 529-570
} 
Douglas Heinz, Jane Iara Pereira da Costa \& Erick William Pereira

\begin{tabular}{|c|c|c|}
\hline ITEM & PONTOS PRINCIPAIS & AUTORES \\
\hline $\begin{array}{l}\text { Problemas para } \\
\text { os participantes }\end{array}$ & $\begin{array}{l}\text { - } \text { Constituição societária } \\
\text { - Permite comportamento oportunista dos } \\
\text { participantes } \\
\text { - Dificuldade em estabelecer mecanismos de controle } \\
\text { e incentivos } \\
\text { - } \quad \text { Lentidão no processo decisório } \\
\text { - } \quad \text { Bitributação } \\
\text { - } \quad \text { Assimetria nas informações } \\
\text { - } \quad \text { Diferentes tamanhos dos participantes } \\
\text { - } \quad \text { Processo de gestão } \\
\text { - } \quad \text { Custo-benefício } \\
\text { - Conflito dos interesses da organização com os } \\
\text { interesses da rede } \\
\text { - Mudanças culturais }\end{array}$ & $\begin{array}{l}\text { Yemal, Fusco e Rospi } \\
\text { (2006); Lima (2007); } \\
\text { Cervi, Razzolini Filho e } \\
\text { Rodriguez (2004); } \\
\text { Morosky (2010); Pousa et } \\
\text { al (2006); Saab, Gimenez, } \\
\text { Ribeiro (2000), Xavier } \\
\text { Filho et al. (2010). }\end{array}$ \\
\hline
\end{tabular}

Fonte: Elaborado pelos autores

No segmento supermercadista, as redes são, para Soares et. al (2011), uma das principais alternativas para o aumento da competitividade de Pequenas e Micro Empresas (PMEs). Além disso, o crescimento constante do faturamento, número de lojas e check-outs e da área de vendas (LUKIANOCENKO, 2010), parece indicar que os benefícios da adesão à uma rede de compras superam os potenciais problemas, estimulando a difusão desta estratégia.

\section{COMPOSTO DE MARKETING}

Kotler (1972), em um de seus trabalhos, já comentava que o Marketing é uma ciência descritiva que envolve o estudo de como as transações são criadas, estimuladas, facilitadas e valorizadas. Com um mercado cada vez mais dinâmico, é necessário que as estratégias de Marketing, desenvolvidas pelos profissionais dessa área, também evoluam junto com o planejamento de longo prazo realizado pelas organizações (BORDEN, 1984). Um Marketing efetivo consiste em inteligentemente analisar, planejar, organizar e controlar os esforços de Marketing (KOTLER, 1972). O conceito de Marketing tem sofrido adaptações ao longo dos anos pelo fato de termos um mercado em constante movimento, sendo necessário adaptar as estratégias de acordo com a época em questão. O composto de marketing é um dos elementos mais impactados por este processo de transformação.

Borden (1984), intitula-se o pioneiro na utilização do termo "marketing mix", ou composto de marketing, na língua portuguesa. Seu trabalho apresenta um modelo conceitual formado por 12 elementos que misturados podem proporcionar melhores resultados em ações mercadológicas desenvolvidas nas organizações. Seguindo a mesma linha, E. Jerone McCarthy propôs posteriormente um modelo mnemônico de marketing mix formado por 
Composto de marketing em redes de compras: estudo comparativo das percepções de administradores e associados em uma rede de supermercados

quatro elementos: product (produto), price (preço), place (praça ou distribuição) e promotion (promoção ou comunicação), que ficaram conhecidos como 4P’s. A facilidade de assimilação e memorização deste conceito o tornou a mais comum classificação de marketing mix (VAN WATERSCHOOT; VAN DEN BULTE, 1992; GRÖNROOS, 1994). De forma objetiva, o quadro 2, adaptado de Mardh e Correia (2013), explica estes elementos.

Quadro 2 - O Composto de Marketing

\begin{tabular}{|c|c|}
\hline ELEMENTO & DEFINIÇÃO \\
\hline Preço & $\begin{array}{r}\text { Valor que o comprador paga por um produto (lista de preços, descontos, } \\
\text { subsídios, prazo de pagamento, condições de crédito) }\end{array}$ \\
\hline Comunicação & $\begin{array}{r}\text { Métodos de comunicação utilizados para prover informações sobre o } \\
\text { produto (promoção de vendas, publicidade, forças de vendas, relações } \\
\text { públicas, marketing direto) }\end{array}$ \\
\hline Produto & $\begin{array}{r}\text { Um item que satisfaz o que o cliente necessita ou quer (variedade de } \\
\text { produtos, qualidade, design, características, marca, embalagem, tamanho, } \\
\text { serviços, garantia, devolução) }\end{array}$ \\
\hline Distribuição & $\begin{array}{c}\text { Disponibilizar um produto em um local conveniente ao consumidor } \\
\text { (canais, cobertura, sortimento, locais, inventário, transporte) }\end{array}$ \\
\hline
\end{tabular}

Fonte: Adaptado de Mardh e Correia (2013)

Atualmente existem sugestões de inclusão de outros elementos ao composto de marketing $^{3}$, mas como nem mesmo os quatro itens básicos são totalmente compreendidos e administrados de forma competente, alcançar a proficiência neles já significa obter bom nível de gestão de marketing. Para tanto, tais elementos devem ter uma consistência vertical, ou seja, estar alinhado aos objetivos estratégicos e de marketing da organização, mas também uma consistência horizontal, onde as ações desenvolvidas para cada um sejam coerentes entre si (URDAN; URDAN, 2006). O marketing mix de longo e curto prazo é apresentado como uma estratégia que deve levar em consideração o mercado atual, cada vez mais dinâmico, e o planejamento de longo prazo realizado pelas organizações (TEIXEIRA; BARBOSA, 2008).

\section{a. Produto}

O produto é o objeto principal da comercialização. Usualmente ele representa um conjunto de atributos básicos montados em uma forma identificável. Em marketing, porém, a

\footnotetext{
${ }^{3}$ Uma análise das propostas de novos elementos para o marketing mix pode ser encontrada, por exemplo em: GOI, Chai LEE. A review of Marketing Mix: 4Ps or More? International Journal of Marketing Studies v.1 n.1 p2-15, mai. 2009
}

REAd | Porto Alegre - Edição 78 - Nº 2 - maio/agosto 2014 - p. 529-570 


\section{Douglas Heinz, Jane Iara Pereira da Costa \& Erick William Pereira}

definição deve ser mais ampla para compreender também os benefícios que satisfazem as necessidades dos consumidores (ETZEL; WALKER; STANTON, 2001). Os serviços podem ser definidos como atos, processos e o desempenho de ações (ZEITHAML; BITNER, 1996).

As forças de mercado podem influenciar o marketing mix, onde o profissional de marketing deve estar atento aos recursos disponíveis a serem utilizados para que produtos e serviços tenham sucesso no mercado (TEIXEIRA; BARBOSA, 2008). Um grupo de produtos com características físicas similares e voltados a usos também similares formam uma linha de produto, enquanto o conjunto de todos os produtos oferecidos para venda por uma empresa representa o mix de produtos (ETZEL; WALKER; STANTON, 2001). No comércio varejista a definição do mix e a linha de produtos impacta no perfil da clientela que se pretende atender, no layout e tamanho da loja, no volume de estoque e no capital de giro requerido para o negócio, além de refletir diretamente no volume de vendas e na rentabilidade da empresa. $\mathrm{O}$ mix de produtos no varejo deve ter foco no consumidor, ser voltado à maximização das vendas e objetivar a minimização dos estoques através de sua correta gestão (INAFUCO 1997).

Outro fator relevante na análise mercadológica do produto é a marca, definida por Urdan e Urdan (2006) como um nome, desenho, símbolo ou combinação destes que são utilizados para identificar e individualizar produtos e/ou suas linhas, organizações, serviços e até mesmo ideias (URDAN; URDAN, 2006). Schutte (1969 apud Pereira 2011) distingue as marcas de acordo com o grupo que as possui ou controla, sendo as marcas de fabricante aquelas sob a responsabilidade de organizações produtoras e marcas de distribuidor aquelas controladas por organizações voltadas à distribuição de mercadorias, como o comércio varejista. Para Urdan e Urdan (2006), a marca própria de varejista utiliza a confiança do consumidor no varejista para encorajar o consumo de produtos com preços menores sem aumentar a percepção de risco, graças à forte imagem da empresa comercializadora, além de simplificar o trabalho do consumidor ao apresentar uma referência prática para o produto.

\section{b. Preço}

O preço, em sentido restrito, é a quantia em dinheiro que se cobra por um produto ou serviço, e de forma mais ampla é a soma de todos os valores que os consumidores trocam pelos benefícios de obter ou utilizar um produto ou serviço. Enquanto os demais componentes do mix de marketing representam custos, o preço produz receita (KOTLER; ARMSTRONG, 2003; URDAN; URDAN, 2006). Ele tem impacto no nível de vendas, na margem de 
Composto de marketing em redes de compras: estudo comparativo das percepções de administradores e associados em uma rede de supermercados

contribuição e na posição estratégica de um produto, tornando-se assim uma das mais relevantes variáveis de marketing (LIMA et al., 2007). Outra característica marcante do preço no composto de marketing é a sua flexibilidade, uma vez que ao contrário das especificações de produtos e dos compromissos com os canais de distribuição, ele pode ser alterado rapidamente (KOTLER; ARMSTRONG, 2003; URDAN; URDAN, 2006). Sobre isto, todavia, Carneiro et al. (2006) alertam que a liberdade das empresas para fixar preços pode ser condicionada por fatores macro ambientais, como inflação, taxa de juros, controles oficiais, políticas tributárias e atuação de organismos de defesa do consumidor.

O preço possui dois componentes. O primeiro é a concepção usual do consumidor, o valor monetário formado pelo preço pago pelo produto acrescido dos custos da operação, manutenção e depreciação do produto. Já o segundo é o não monetário, que envolve os custos psicológicos, de tempo e energia gastos para adquirir e utilizar um produto (URDAN; URDAN, 2006). O preço faz parte de um posicionamento maior da empresa definido por suas estratégias e pelo seu composto de marketing, portanto, as decisões sobre ele devem ser coerentes com as demais decisões de marketing e com a orientação estratégica da empresa, permitindo assim que o preço contribua para o posicionamento desejado no mercado (CARNEIRO, et al., 2006).

\section{c. Comunicação}

A comunicação ou promoção é o elemento do mix de marketing que objetiva exercer influência sobre as crenças ou comportamentos de um público-alvo, informando, persuadindo e lembrando o mercado de um produto e/ou organização que o vende (ETZEL; WALKER; STANTON, 2001). Ela completa o composto de marketing ajudando a conquistar e manter os clientes, além de comunicar-se com outros grupos de interesse como distribuidores, acionistas e comunidade (URDAN; URDAN, 2006).

O cumprimento das funções de promoção passa pela utilização de diversos instrumentos. Kotler e Armstrong (2003) sugerem um mix de comunicações em marketing composto por cinco elementos: a propaganda é qualquer forma paga de apresentação e promoção não pessoal de ideias, bens ou serviços por um patrocinador identificado; a venda pessoal é uma apresentação feita por força de vendas da empresa objetivando vender e desenvolver relacionamentos; a promoção de vendas trata de incentivos de curto prazo para estimular a compra ou venda de um produto; as relações públicas consistem no desenvolvimento de boas relações com os diversos públicos da empresa para obtenção de REAd | Porto Alegre - Edição 78 - Nº 2 - maio/agosto 2014 - p. 529-570 


\section{Douglas Heinz, Jane Iara Pereira da Costa \& Erick William Pereira}

publicidade favorável, construção de uma boa imagem corporativa e administração ou impedimento da disseminação de mensagens negativas sobre a organização; e o marketing direto caracteriza-se pelo contato direto com consumidores individuais cuidadosamente definidos como alvo, utilizando para isso ferramentas como fax, telefone, e-mail e internet.

Outro recurso da comunicação em marketing é a publicidade. Santos (2005) esclarece que o propósito imediato da publicidade não é concretizar transações, predispor as pessoas a uma proposição de troca, através do anúncio das vantagens desta troca. Para Armstrong (2011) as empresas se preocupam com algumas estratégias bem específicas neste sentido, como: comunicar uma oferta única como forma de atrair o cliente para a loja; dizer algo relevante no primeiro parágrafo; incluir a marca e nome de empresas; e promover notícias, porém apenas se forem reais. Neste sentido, Retseptor (2005) comenta que um dos principais princípios a ser seguido pelo marketing é a segmentação de acordo com a necessidade dos clientes, dividindo os mesmos em grupos de prospects que tenham necessidades em comum e com isso dividir a comunicação da empresa por categoria de clientes. Este autor ainda afirma que atualmente é necessário focar em consumidores através de estratégias one to one, quando se pensa que cada consumidor pode ser um mercado. Muitas empresas já estão trabalhando estratégias de amostragem personalizadas e propaganda em mini-kits para os clientes no PDV.

\section{d. Distribuição}

A distribuição ou ponto-de-venda trata de fazer os produtos chegarem até os clientes com eficiência e eficácia. Para atender este objetivo é utilizado um canal de distribuição, que é o conjunto de organizações interdependentes envolvidas no processo de tornar um produto ou serviço disponível para uso ou consumo (LIMA et al., 2007). O canal de distribuição proporciona ao cliente satisfação ou utilidade de lugar, de tempo e de posse. A utilidade de lugar está relacionada à conveniência da obtenção de um produto onde se deseja, enquanto a utilidade de tempo permite a compra quando necessário, e a utilidade de posse gera benefícios mais amplos do que os de aquisição, como status e estilo de vida (LAS CASAS, 2008).

Um canal de distribuição de produtos para consumo pode ser formado por fabricantes, atacadistas, distribuidores e varejistas (KOTLER; ARMSTRONG, 2003). O Distribuidor é um agente de distribuição que compra e vende produtos de fornecedores na indústria, com os quais possui vínculo de exclusividade de produtos e/ou de territórios (ASSOCIAÇÃO BRASILEIRA DE ATACADISTAS E DISTRIBUIDORES - ABAD, 2010). As atividades do atacadista são aquelas relacionadas à venda de produtos e serviços para revenda ou uso 
Composto de marketing em redes de compras: estudo comparativo das percepções de administradores e associados em uma rede de supermercados

industrial, geralmente fornecendo produtos para o varejo (LAS CASAS, 2008). A existência de atacadistas pode ser justificada por sua capacidade de realizar melhor algumas funções do canal de distribuição, como vendas e promoção, compras e formação de sortimento, quebra de lotes, armazenagem, transporte, financiamento, absorção de riscos, fornecimento de informações de mercado e serviços de gerenciamento e consultoria (KOTLER; ARMSTRONG, 2003).

As atividades de varejo, no âmbito dos canais de distribuição, são aquelas voltadas à venda de produtos e serviços para consumidores finais. Dentre as ações desenvolvidas no varejo estão criar um local, físico ou virtual, para a venda, promover e expor os produtos, atrair, receber e colocar clientes em potencial em contato com as ofertas, prestar explicações sobre os produtos, negociar condições de venda e cuidar da entrega das mercadorias (URDAN; URDAN, 2006). Pride e Ferrell (2001) argumentam que os varejistas são importantes por agregar valor, prestar serviços e prover assistência na escolha de produtos, além de facilitar a compra por comparação através de sua localização e aumentar o valor do produto quando são oferecidos serviços adicionais, enquanto Belik (1997) salienta que o processo de concentração dos mercados tende a tornar o varejo uma atividade sofisticada, deixando de ser caracterizado como algo reservado a poucos empresários dotados de sensibilidade comercial para ser também uma atividade de apuro técnico e fundamentação empresarial.

\section{VAREJO SUPERMERCADISTA}

Inicialmente ligado à exploração das riquezas naturais da então colônia de Portugal, ao tráfego de escravos e ao movimento de tropeiros pelo interior do país, é a partir do final da II Guerra Mundial que o comércio brasileiro passa a modernizar-se. Surgem lojas de departamentos com estacionamento e lanchonete, além de lojas especializadas em roupas. É introduzido o conceito de autosserviço e em 1953 é instalado o primeiro supermercado do Brasil, na Rua da Consolação em São Paulo (VAROTO, 2006; LAS CASAS, 2008).

A partir de 1970 o comércio varejista no Brasil inicia um processo de concentração, derivado, entre outros, da instalação de varejistas estrangeiros e do desenvolvimento de um novo modelo de lojas, o hipermercado, oferecendo vários grupos de produtos serviços em um mesmo local e contando ainda com instalações sofisticadas e grande variedade de itens. Recentemente, as novas tecnologias da informação e o comércio eletrônico, impulsionados pela disseminação da internet, têm provocado mudanças neste setor, que continua em 
Douglas Heinz, Jane Iara Pereira da Costa \& Erick William Pereira

processo de concentração, mas ao mesmo tempo observa reações dos pequenos comércios, além do surgimento de novos formatos de lojas, bem como a difusão e ampliação de vendas realizadas em Shoppings Centers (VAROTTO, 2006).

Atualmente o varejo é um dos mais importantes componentes da economia nacional. Segundo dados do Instituto Brasileiro de Geografia e Estatística - IBGE (2010a), em 2008 havia cerca de 1,4 milhões de empresas de varejo no Brasil, ocupando mais de 8 milhões de pessoas entre assalariados, proprietários e membros de família. Em 2008 (IBGE, 2010b), a receita operacional líquida dos varejistas foi de 576 bilhões de reais, o que representou cerca de 20\% (vinte por cento) do PIB (Produto Interno Bruto) brasileiro no período. Dados da Associação Brasileira de Supermercados - ABRAS (2010), indicam o faturamento anual do setor na faixa de 177 bilhões de reais, através de 78.311 lojas que contam com 191.512 checkouts, em uma área de vendas de 19,2 milhões de metros quadrados, totalizando 899.754 funcionários.

Nos últimos dez anos, as centrais de negócios do segmento supermercadista, segundo Lukianocenko (2010), aumentaram a sua representatividade em vendas de 3\% (três por cento) para 13,3\% (treze vírgula três por cento), sendo faturados, em 2009, mais de vinte e um bilhões de reais. O número de lojas vinculadas a alguma rede é de 3.540, com 19.905 checkouts e uma área de vendas de 2,21 milhões de metros quadrados. A tabela 1 resume estes dados.

Tabela 1 - Dados das redes de compras de supermercados entre 2005 e 2009

\begin{tabular}{c|c|c|c|c|c|c}
\hline & $\mathbf{2 0 0 5}$ & $\mathbf{2 0 0 6}$ & $\mathbf{2 0 0 7}$ & $\mathbf{2 0 0 8}$ & $\mathbf{2 0 0 9}$ & $\begin{array}{c}\mathbf{2 0 0 9} \mathbf{x} \\
\mathbf{2 0 0 8}\end{array}$ \\
\hline $\begin{array}{c}\text { Faturamento bruto (em } \\
\text { bilhões de reais) }\end{array}$ & $\mathrm{R} \$ 14,2$ & $\mathrm{R} \$ 15,9$ & $\mathrm{R} \$ 17,65$ & $\mathrm{R} \$ 19,84$ & $\mathrm{R} \$ 21,09$ & $6,54 \%$ \\
\hline $\begin{array}{c}\text { Número } \\
\text { de Lojas }\end{array}$ & 3.056 & 3.214 & 3.410 & 3.500 & 3.540 & $1 \%$ \\
\hline $\begin{array}{c}\text { Número de } \\
\text { Check-outs }\end{array}$ & 13.667 & 14.240 & 16.150 & 17.700 & 19.905 & $7,60 \%$ \\
\hline $\begin{array}{c}\text { Área de vendas (milhões } \\
\text { de } \text { m }^{2} \text { ) }\end{array}$ & 1,56 & 1,95 & 2,10 & 2,14 & 2,21 & $3,20 \%$ \\
\hline
\end{tabular}

Fonte: Lukianocenko (2010)

Atualmente o setor supermercadista brasileiro está polarizado entre grandes corporações resultantes de fusões e aquisições e pequenos supermercados geralmente pulverizados e com atuação dispersa e desorganizada (HIROSHI ${ }^{4}, 2000$ apud GHISI; DE CAMARGO; MARTINELLI, 2003). Por isto, varejistas que se organizam em centrais de

\footnotetext{
${ }^{4}$ HIROSHI, W.A. A concentração e pulverização do varejo no Brasil.
}

REAd | Porto Alegre - Edição 78 - N 2 - maio/agosto 2014 - p. 529-570 
Composto de marketing em redes de compras: estudo comparativo das percepções de administradores e associados em uma rede de supermercados

negócios, ao que parece, encontram uma estratégia para reagir a um cenário aparentemente desfavorável, oportunizando a continuidade e expansão de seus negócios.

\section{PROCEDIMENTOS METODOLÓGICOS}

A pesquisa realizada é de modalidade exploratória, que visa a descoberta, a elucidação de fenômenos ou a explicação daqueles que não eram aceitos apesar de evidentes (JUNG, 2004). A exploração de dados permite, entre outros, desenvolver conceitos de forma mais clara e estabelecer prioridades. Estudos exploratórios normalmente utilizam com maior frequência métodos qualitativos (COOPER; SCHINDLER, 2003), que são mais subjetivos e envolvem examinar e refletir as percepções para obter um entendimento de atividades sociais e humanas (COLLIS; HUSSEY, 2005).

Este trabalho é do tipo estudo de caso, sendo objeto da pesquisa uma rede de compras formada por 35 (trinta e cinco) pequenos supermercados da região do Alto Vale do Itajaí, estado de Santa Catarina. Além da conveniência, esta rede foi escolhida por ser considerada como case de sucesso pelo SEBRAE (Serviço Brasileiro de Apoio às Micro e Pequenas Empresas) de Santa Catarina, segundo informações disponíveis em seu web site. Justifica-se a utilização do estudo de caso em uma rede com contingente pequeno de associados por sua adequação ao caráter exploratório e aos objetivos do trabalho, pois como argumenta Yin (2005), este método apresenta a vantagem de permitir investigar preservando as características holísticas e significativas de acontecimentos da vida real, como processos organizacionais e administrativos, entre outros.

Dois foram os grupos de interesse da pesquisa: os administradores e os associados da rede. Para a pesquisa junto aos administradores utilizou-se a abordagem qualitativa, formulada a partir de descrições intuitivas do pesquisador ou do indivíduo pesquisado, com a finalidade de representar os objetos ou indivíduos e as relações associadas para a formulação de um modelo interativo (JUNG, 2004). A técnica adotada foi a entrevista em profundidade, tendo como instrumento roteiro semi-estruturado (apêndice 1). Gressler (2003) afirma que as entrevistas abertas e semi-abertas são instrumentos básicos de investigação na pesquisa qualitativa, e que entrevistas semi-estruturadas são construídas em torno de um corpo de questões do qual o entrevistador parte para uma exploração em profundidade. Participaram da entrevista, que teve duração de aproximadamente uma hora, o presidente e o gerente operacional da rede. 


\section{Douglas Heinz, Jane Iara Pereira da Costa \& Erick William Pereira}

A pesquisa com associados foi realizada através de abordagem quantitativa. Moura e Ferreira (2005) esclarecem que dados quantitativos são aqueles apresentados sob forma numérica ou que podem ser diretamente convertidas a ele. Para Jung (2004), a pesquisa quantitativa utiliza a elaboração de enunciados analíticos e a descrição matemática das variáveis e relações existentes entre as mesmas. Utilizou-se como instrumento de pesquisa o questionário (apêndice 2), e a aplicação foi conduzida por correspondência, forma escolhida em função da distância geográfica entre as empresas.

O envio do questionário por correio eletrônico foi acompanhado de texto explicativo sobre os objetivos da pesquisa. Não foi enviado questionário para a empresa do presidente da rede de supermercados porque ele participou da entrevista da etapa qualitativa. De Pádua (1989) afirma que para pesquisas onde há muitos entrevistados ou quando estes não residem no local, pode-se enviar os questionários por correspondência, desde que acompanhados de uma carta de apresentação. Para Cooper e Schindler (2003), pesquisas por correspondência têm como vantagens o menor custo de aplicação, a maior impessoalidade percebida pelos respondentes e o maior tempo disponível para análise e levantamento de informações que garantam a correção das respostas. Já o principal problema apontado neste tipo de pesquisa é o erro de não-resposta, sendo um índice de retorno de 30\% (trinta por cento) satisfatório.

Considerando estes premissas, neste estudo adotou-se a estratégia do acompanhamento. Uma e duas semanas após o envio dos questionários foram realizados contatos telefônicos e envio de lembretes por e-mail para os não respondentes. Obteve-se índice de retorno de 41\% (14 respostas de 34 associados participantes), que apesar de pequeno, se justifica como aceitável caráter exploratório da pesquisa, além do percentual de respostas ficar acima do mínimo apontado como satisfatório por Cooper e Schindler (2003).

Utilizou-se a análise de discurso como estratégia para a interpretação dos resultados obtidos na pesquisa com os administradores, classificando as respostas em categorias de análise. A classificação de elementos seguindo critérios determinados é denominada categorização, sendo que dentre as suas possibilidades de utilização a mais comum, rápida e eficaz, quando aplicada a conteúdos diretos, é a análise por temas ou temática (RICHARDSON, 1999). Utilizando a categorização temática foram elencados como categorias de análise os aspectos gerais de formação e desenvolvimento da rede e os elementos do composto de marketing: produto, preço, comunicação e distribuição.

$\mathrm{Na}$ análise quantitativa, inicialmente realizou-se o cálculo da frequência das respostas obtidas. Para Cooper e Schindler (2003), este procedimento orienta a escolha da análise a ser 
Composto de marketing em redes de compras: estudo comparativo das percepções de administradores e associados em uma rede de supermercados

adotada, ao invés de vez de a análise presumida sobrepor sua estrutura sobre os dados. As tabelas de frequência e gráficos estão entre as principais ferramentas sugeridas pelos autores para esta etapa da pesquisa. A distribuição de frequência, complementam Rea e Parker (2000), é uma apresentação sumária da frequência das respostas de cada categoria variável, e dentre as suas vantagens, Cooper e Schindler (2003) destacam a simplicidade para ordenação de dados. A partir da análise da distribuição de frequências foi calculado o coeficiente de correlação de Pearson e o coeficiente de determinação dos dados, visando identificar quais as características explicam o nível de satisfação dos associados em relação à rede. Segundo Barbetta (2001), o coeficiente de correlação de Pearson é adequado para descrever a correlação linear entre duas variáveis, e o coeficiente de determinação é uma medida descritiva da proporção da variação de uma variável dependente que pode ser explicada por uma variável independente.

Finalmente, os resultados obtidos junto aos administradores e associados foram organizados em quadros abrangendo as categorias de análise definidas, permitindo a comparação das percepções destes atores sobre as ações da rede relacionadas ao composto de marketing.

\section{APRESENTAÇÃO DOS RESULTADOS}

Nesta seção são apresentados e discutidos os resultados do trabalho realizado.

\section{a. Formação e administração da rede}

Os administradores da rede atribuíram o surgimento da rede ao processo natural de aprimoramento de experiências anteriores dos varejistas participantes, que já estavam predispostos a participar de arranjos associativos, mesmo que informais, na tentativa de adaptar-se às exigências do mercado em seus segmentos. Infere-se, desta constatação, que esta rede teve origem em um movimento de coevolução que gerou uma nova forma organizacional, processo que vem ao encontro do proposto por Lewin, Long e Carroll (1999).

Sobre a administração e funcionamento da rede, as respostas dos associados indicam que apesar da aprovação quanto aos procedimentos adotados ainda há oportunidades que podem ser exploradas pela rede, especialmente com o aumento da participação no volume total de compras dos associados, de forma que os benefícios obtidos se estendam ao maior número possível de produtos. Procedimentos para seleção de associados, a organização em forma de comissões e o processo decisório participativo também se destacam positivamente, 
formando um conjunto de características que parecem dar sustentação ao modelo de organização da rede. O quadro 3 resume esta análise.

Quadro 3 - Análise comparativa das características gerais da rede

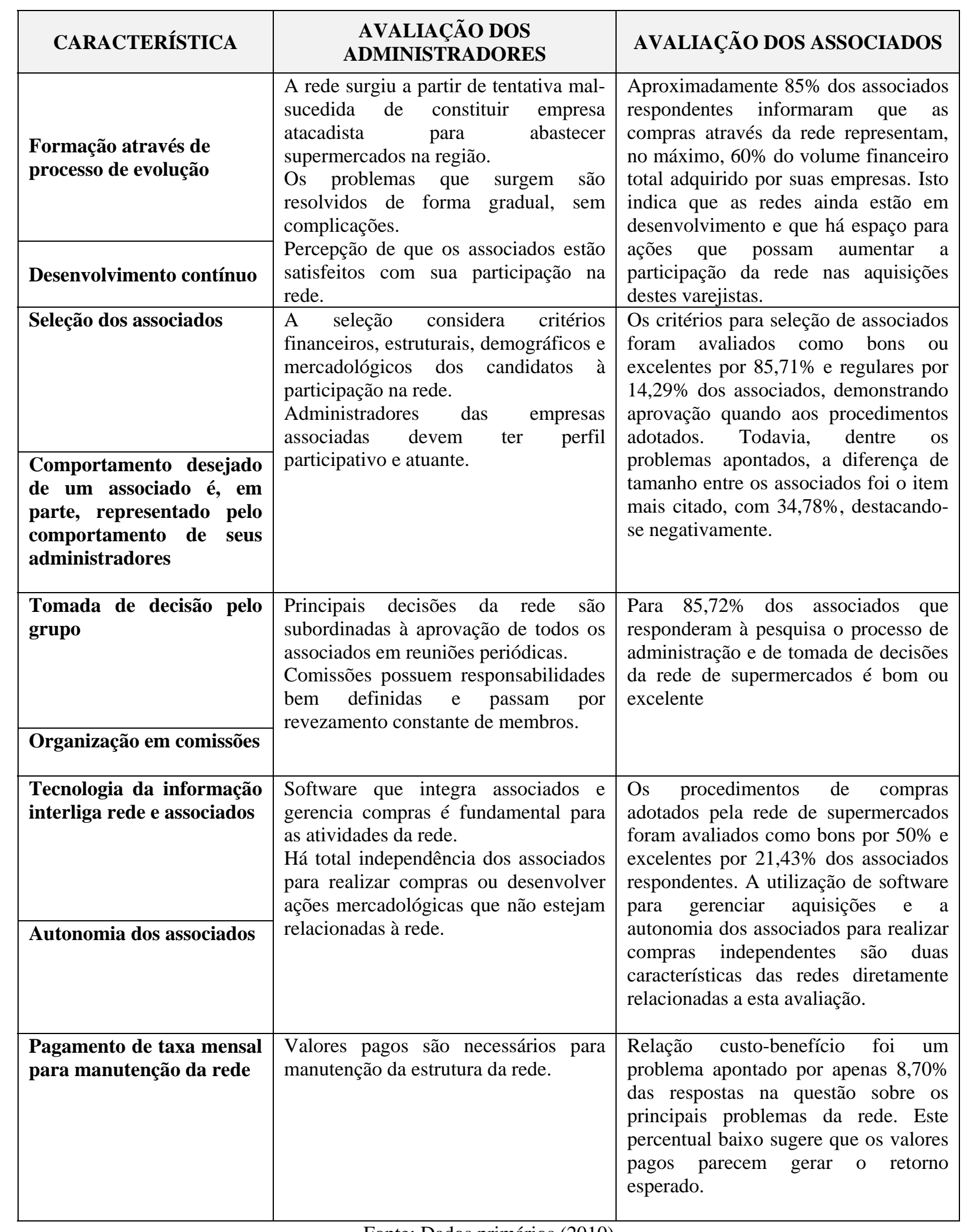

Fonte: Dados primários (2010) 
Composto de marketing em redes de compras: estudo comparativo das percepções de administradores e associados em uma rede de supermercados

A percepção dos administradores de que os associados estão satisfeitos com a sua participação na rede é confirmada pelas respostas obtidas. Houve aprovação quanto aos procedimentos adotados e nenhum dos problemas relatados obteve destaque, nem mesmo os valores pagos regularmente para a manutenção da rede, que foram avaliados em relação ao seu custo-benefício.

Buscou-se também conhecer o nível de satisfação dos associados. Para tanto foi realizado o cálculo do coeficiente de correlação r de Pearson, utilizando a satisfação geral como variável dependente e o volume de compras feitas por intermédio da rede como variável independente. $\mathrm{O}$ resultado obtido, $\mathrm{r}=0,564879$, indica que o volume adquirido correlaciona-se positivamente com a satisfação dos associados, ou seja, quanto mais utiliza a rede, mais satisfeito se torna o associado. Considerando as faixas para determinação de grandeza de um efeito estipuladas por Cohen (1992 apud Field, 2009), em que $r=0,10$ o efeito é pequeno, $r=$ 0,30 o efeito é médio e $r=0,50$ o efeito é grande, o teste aplicado indica que a correlação identificada é forte.

Através do cálculo do coeficiente de determinação $\left(\mathrm{R}^{2}\right)$ dos dados, com resultado 0,3190, observa-se que aproximadamente $32 \%$ da satisfação pode ser explicada pelo volume de compras. O gráfico de dispersão a seguir representa a correlação entre o volume de compras e a satisfação dos associados.

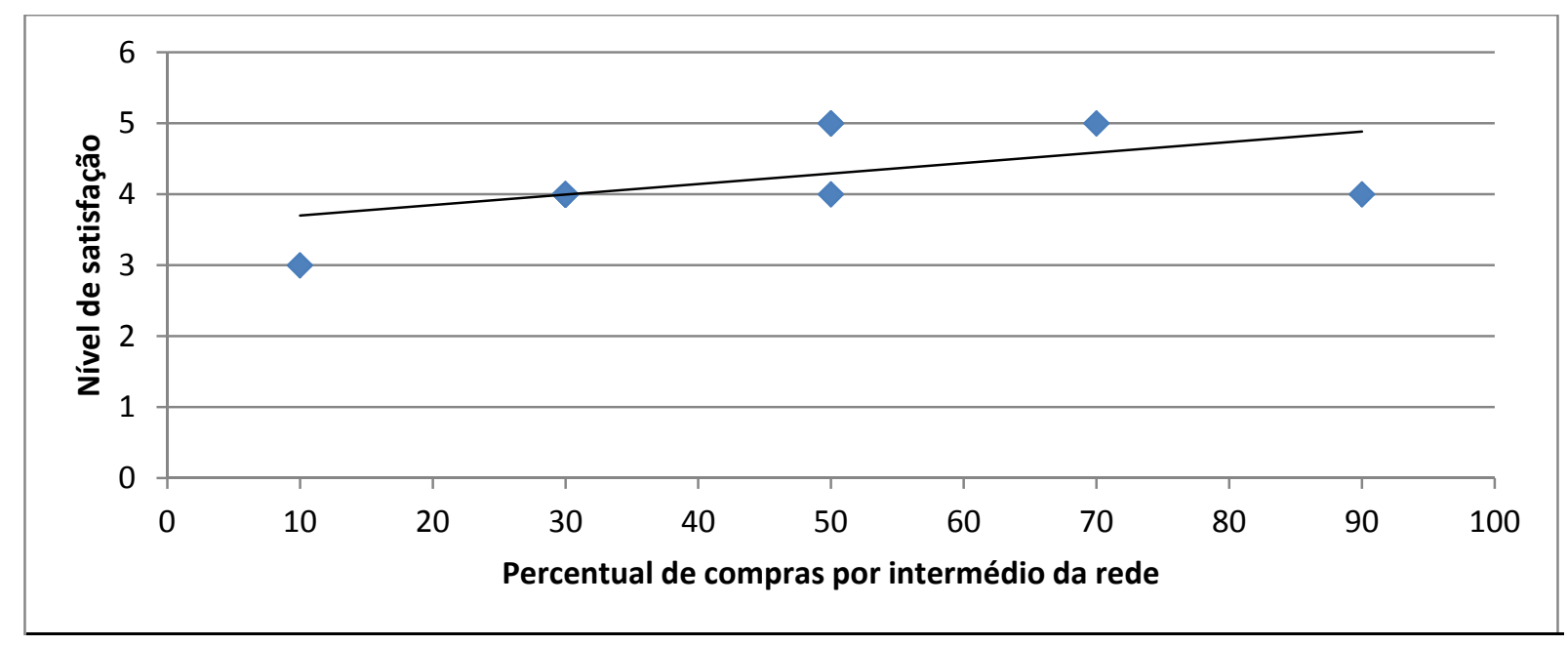

Gráfico 1 - Utilização da rede x nível de satisfação Fonte: dados Primários (2010)

Além das características gerais, as ações relacionadas ao composto de marketing nas redes de compras também podem ser comparadas em relação às percepções de administradores e associados.

REAd | Porto Alegre - Edição 78 - N 2 - maio/agosto 2014 - p. 529-570 
Douglas Heinz, Jane Iara Pereira da Costa \& Erick William Pereira

\section{b. Composto de marketing}

Os administradores relataram haver total independência dos associados sobre a definição do mix de marcas e produtos oferecidos nos supermercados. Neste sentido, decidir quais os produtos do mix que seriam comuns a todos os associados parece ser o grande desafio, pois como lembrou bem o administrador da rede "não somos nós que descartamos, é o próprio cliente na ponta que acaba descartando o novo produto”. É interessante notar ainda que mais de $90 \%$ dos associados respondentes relataram aumento na variedade de marcas, e 100\% afirmaram haver aumento na variedade de produtos oferecidos pela empresa após sua adesão à rede, indicando que a participação aumenta a possibilidade de acessar produtos e fornecedores que não estão ao alcance de pequenos negócios que atuam isoladamente.

Em relação à adoção de marcas próprias, o pensamento de administradores e associados parece divergir. Enquanto que a medida é vista com cautela pelos dirigentes, para cerca de dois terços dos sócios esta estratégia é considerada oportuna. Já existindo na rede uma linha de produtos de marca própria (massas), as diferentes percepções identificadas apontam que esta estratégia ainda não está consolidada.

O quadro 4 resume as constatações da pesquisa sobre o elemento produto do composto de marketing.

Quadro 4 - Análise comparativa das ações do item produto do composto de marketing

\begin{tabular}{|c|c|c|}
\hline CARACTERÍSTICA & $\begin{array}{c}\text { AVALIAÇÃO DOS } \\
\text { ADMINISTRADORES }\end{array}$ & AVALIAÇÃO DOS ASSOCIADOS \\
\hline $\begin{array}{l}\text { Independência dos } \\
\text { membros na definição do } \\
\text { mix de produtos }\end{array}$ & \multirow[t]{2}{*}{$\begin{array}{l}\text { Atualmente não há qualquer } \\
\text { interferência da rede na decisão dos } \\
\text { associados sobre quais produtos e } \\
\text { marcas serão comercializados, ou } \\
\text { quais serviços serão oferecidos pelos } \\
\text { associados. Há um projeto, } \\
\text { denominado } 100 \% \text {, em que a } \\
\text { padronização será analisada. }\end{array}$} & $\begin{array}{l}\text { Todos os associados da rede de } \\
\text { compras que responderam à pesquisa } \\
\text { indicaram que a variedade de produtos } \\
\text { comercializados pela empresa } \\
\text { aumentou. Quanto à variedade de } \\
\text { marcas, apenas } 7,14 \% \text { apontaram que } \\
\text { manteve-se igual, enquanto todos os } \\
\text { demais afirmaram que houve aumento. }\end{array}$ \\
\hline $\begin{array}{l}\text { Independência dos } \\
\text { membros na definição dos } \\
\text { serviços associados }\end{array}$ & & $\begin{array}{l}\text { A padronização dos serviços oferecidos } \\
\text { pela rede foi considerada importante ou } \\
\text { muito importante por todos os } \\
\text { associados que responderam à } \\
\text { pesquisa. }\end{array}$ \\
\hline $\begin{array}{l}\text { Existência de marca } \\
\text { própria de produtos }\end{array}$ & $\begin{array}{l}\text { Há uma linha de produtos com marca } \\
\text { própria (massas), porém o tema é } \\
\text { visto com cautela. Preocupação em } \\
\text { evitar que percepções negativas sobre } \\
\text { produtos reflitam na marca da rede. }\end{array}$ & $\begin{array}{l}\text { Para } 71,43 \% \text { dos associados, produtos } \\
\text { com marca própria são considerados } \\
\text { importantes ou muito importantes, } \\
\text { enquanto } 14,29 \% \text { mostraram-se } \\
\text { indiferentes e } 14,29 \% \text { consideram esta } \\
\text { ação nada ou pouco importante. }\end{array}$ \\
\hline
\end{tabular}

Fonte: Dados primários (2010) 
Composto de marketing em redes de compras: estudo comparativo das percepções de administradores e associados em uma rede de supermercados

A redução dos preços de aquisição derivada do aumento do volume negociado é um dos pressupostos da formação de redes de compras. Na pesquisa, administradores e associados da rede de supermercados afirmaram que são obtidos descontos significativos na realização de compras conjuntas, o que acaba refletindo na percepção dos clientes. Para os associados, o item redução nos preços de compras foi o segundo mais citado, com 23,81\% das respostas, na questão sobre as motivações para adesão à rede. Além disso, mais de $90 \%$ consideram que a associação possibilita obter preços um pouco ou muito menores do que seria possível comprando individualmente. Estes resultados contrapõem-se ao observado por Ghisi, De Camargo e Martinelli (2003 p. 238), que estudando redes supermercadistas constataram que "em relação à compra de produtos, pôde-se perceber que os descontos conseguidos pela rede de compra com os fornecedores ainda não são muito expressivos”.

A comparação das respostas de administradores e associados encontra-se no quadro 5, a seguir.

Quadro 5 - Análise comparativa das ações do item preço do composto de marketing

\begin{tabular}{|c|c|c|}
\hline CARACTERÍSTICA & $\begin{array}{l}\text { AVALIAÇÃO DOS } \\
\text { ADMINISTRADORES }\end{array}$ & AVALIAÇÃO DOS ASSOCIADOS \\
\hline $\begin{array}{l}\text { Obtenção de descontos } \\
\text { considerados significativos } \\
\text { na compra em rede }\end{array}$ & $\begin{array}{l}\text { Descontos obtidos são significativos, } \\
\text { em alguns casos chegam até a 30\%. }\end{array}$ & $\begin{array}{l}\text { O aumento da competitividade } \\
\text { (26,19\%) e a redução dos preços de } \\
\text { compras (23,81\%) foram os principais } \\
\text { motivos para a participação na rede } \\
\text { segundo os associados respondentes. } \\
\text { Além disso, 92,86\% destes associados } \\
\text { indicaram que os preços obtidos em } \\
\text { uma compra através da rede são um } \\
\text { pouco ou muito menores do que em } \\
\text { negociações individuais. }\end{array}$ \\
\hline $\begin{array}{l}\text { Independência dos } \\
\text { associados para definir os } \\
\text { preços praticados }\end{array}$ & $\begin{array}{l}\text { Produtos que participam de promoção } \\
\text { mensal (tabloide) possuem preços } \\
\text { padronizados. Para os demais, a } \\
\text { exemplo do que ocorre com questões } \\
\text { relacionadas aos produtos, não há } \\
\text { interferência da rede, porém projeto em } \\
\text { desenvolvimento pode modificar esta } \\
\text { situação. }\end{array}$ & $\begin{array}{l}\text { Para } 71,43 \% \text { dos associados } \\
\text { respondentes, os preços praticados após } \\
\text { a adesão à rede são um pouco ou muito } \\
\text { menores do que quando atuavam } \\
\text { individualmente. Além disso, } 85,71 \% \\
\text { destes associados indicaram que os } \\
\text { clientes percebem os preços de sua } \\
\text { empresa como menores que os dos } \\
\text { concorrentes devido à vinculação com } \\
\text { a rede. Uma eventual padronização dos } \\
\text { descontos por todas as empresas } \\
\text { vinculadas à rede é considerada nada } \\
\text { importante por } 21,43 \% \text { dos associados, } \\
\text { enquanto 35,71\% manifestaram } \\
\text { indiferença e } 42,85 \% \text { consideram esta } \\
\text { ação importante ou muito importante. }\end{array}$ \\
\hline $\begin{array}{l}\text { Independência dos } \\
\text { associados para definir a } \\
\text { condições de pagamento } \\
\text { oferecidas. }\end{array}$ & $\begin{array}{l}\text { Sem interferência da rede, porém } \\
\text { projeto em desenvolvimento pode } \\
\text { modificar esta situação. }\end{array}$ & $\begin{array}{l}\text { Uma eventual padronização das formas } \\
\text { de pagamentos por todas as empresas } \\
\text { vinculadas à rede é considerada nada } \\
\text { importante por } 14,29 \% \text { dos associados, }\end{array}$ \\
\hline
\end{tabular}


Douglas Heinz, Jane Iara Pereira da Costa \& Erick William Pereira

\begin{tabular}{|l|l|l|}
\hline \multicolumn{1}{|c|}{ CARACTERÍSTICA } & \multicolumn{1}{|c|}{$\begin{array}{c}\text { AVALIAÇÃO DOS } \\
\text { ADMINISTRADORES }\end{array}$} & AVALIAÇÃO DOS ASSOCIADOS \\
\hline & & $\begin{array}{l}\text { enquanto 28,57\% manifestaram } \\
\text { indiferença e 57,14\% consideram esta } \\
\text { ação importante ou muito importante. }\end{array}$ \\
\hline $\begin{array}{l}\text { Associados pagam as } \\
\text { compras para a rede }\end{array}$ & $\begin{array}{l}\text { Sistema é adequado. O regime fiscal da } \\
\text { rede elimina problemas de bitributação. }\end{array}$ & $\begin{array}{l}\text { Para 42,86\% dos associados } \\
\text { respondentes as formas de pagamento à } \\
\text { rede são regulares. Os demais } \\
\text { consideram este procedimento como } \\
\text { bom ou excelente. }\end{array}$ \\
\hline
\end{tabular}

Fonte: Dados primários (2010)

Apesar dos administradores pregarem a total autonomia dos associados quanto à realização de campanhas promocionais pelos associados, evidenciou-se que principalmente em relação à propaganda, a comunicação desenvolvida pela rede é a principal forma de divulgação dos associados. O folheto de ofertas (tabloide) é o recurso predominante na comunicação com os consumidores e obteve avaliação positiva pelos associados.

Deve-se considerar, todavia, que a promoção de vendas “[...] deve ocorrer em períodos predeterminados para que seja uma forma motivacional; caso contrário, fica incorporada na estratégia da empresa” (LAS CASAS, 2008, p. 396). Apesar de receber aprovação unânime dos associados, os administradores informaram que os folhetos de oferta são regularmente apresentados aos clientes. Desta forma, há o risco da estratégia, em longo prazo, tornar-se inadequada.

Os associados da rede possuem autonomia para realizar comunicação independente daquela planejada e patrocinada pela rede, o que aumenta a exposição das lojas que passam a contar com dupla promoção, mas também pode gerar confusões e criar diferentes percepções nos consumidores, tanto sobre a própria loja como também em relação à rede. Evidenciou-se na pesquisa que todos os associados respondentes realizam propaganda por conta própria, mas $85,71 \%$, apenas poucas vezes, o que demonstra que a estratégia promocional adotada pela rede acaba sendo também a dos seus associados.

Na entrevista realizada com os administradores, não foi identificada a utilização planejada de outras ferramentas de publicidade pela rede, motivo pelo qual este tema não foi pesquisado junto aos associados. 
Composto de marketing em redes de compras: estudo comparativo das percepções de administradores e associados em uma rede de supermercados

Quadro 6 - Análise comparativa das ações do item comunicação do composto de marketing

\begin{tabular}{|l|l|l|}
\hline \multicolumn{1}{|c|}{ CARACTERÍSTICA } & \multicolumn{1}{|c|}{$\begin{array}{c}\text { AVALIAÇÃO DOS } \\
\text { ADMINISTRADORES }\end{array}$} & AVALIAÇÃo DOS ASSOCIADOS \\
\hline $\begin{array}{l}\text { Promoção de preços } \\
\text { periódica através de } \\
\text { tabloides }\end{array}$ & $\begin{array}{l}\text { Comissão em que há o rodízio de } \\
\text { associados formata tabloide mensal de } \\
\text { ofertas com cinquenta a sessenta itens. } \\
\text { Aplicação depende da aprovação dos } \\
\text { associados. }\end{array}$ & $\begin{array}{l}\text { Todos os associados respondentes } \\
\text { avaliaram esta promoção como boa ou } \\
\text { excelente. }\end{array}$ \\
\hline Realização de sorteios & $\begin{array}{l}\text { Desenvolvida anualmente promoção } \\
\text { com sorteio de prêmios. }\end{array}$ & $\begin{array}{l}\text { Todos os associados respondentes } \\
\text { consideraram os sorteios bons ou } \\
\text { excelentes. }\end{array}$ \\
\hline $\begin{array}{l}\text { Associados realizam } \\
\text { propaganda por conta } \\
\text { própria }\end{array}$ & $\begin{array}{l}\text { Total autonomia dos associados para } \\
\text { realizar propaganda autônoma. Em } \\
\text { andamento padronização das fachadas } \\
\text { dos associados. }\end{array}$ & $\begin{array}{l}\text { Apesar da autonomia para realizar } \\
\text { propagandas individuais, 85,71\% dos } \\
\text { associados respondentes informaram } \\
\text { adotar este procedimento poucas vezes. } \\
\text { As propagandas patrocinadas pela rede } \\
\text { são a principal ferramenta de } \\
\text { comunicação dos varejistas. }\end{array}$ \\
\hline $\begin{array}{l}\text { Existência de canais de } \\
\text { comunicação entre os } \\
\text { membros }\end{array}$ & $\begin{array}{l}\text { Troca de informações é valiosa. } \\
\text { Permite compartilhar experiências e } \\
\text { gera ideias que muitas vezes são } \\
\text { aproveitadas pelos associados. }\end{array}$ & $\begin{array}{l}\text { A comunicação entre os associados foi } \\
\text { avaliada como regular por 28,57\% dos } \\
\text { respondentes, boa por 57,14\% e } \\
\text { excelente por 14,29\%. }\end{array}$ \\
\hline
\end{tabular}

Fonte: Dados primários (2010)

A existência de uma instalação física (Centro de distribuição) é a principal característica da distribuição da rede. Além dos maiores volumes gerados por este arranjo, ao centralizar as entregas de produtos em um único ponto, os negociadores também podem utilizar este fato para aumentar seu poder de barganha junto aos fornecedores. Outra vantagem decorrente desta opção é que com o recebimento de todos os pedidos nos centros de distribuição, as mercadorias de diferentes fornecedores podem ser consolidadas em um único embarque para cada associado, gerando novamente o benefício de redução de custo de transporte pela movimentação de maiores volumes. A existência de um centro de distribuição ainda gera a vantagem da flexibilização, pois em alguns casos as quantidades de compras individuais justificam o transporte direto ao associado, permitindo que os negociadores das redes analisem as propostas para decidir sobre a utilização ou não do centro de distribuição. A ampla aprovação dos associados quanto à utilização do centro de distribuição indica claramente a importância desta instalação no contexto da estratégia de marketing de uma rede de compras.

Ao concentrar as necessidades comerciais de diversos varejistas em uma central de compras, as redes acabam assumindo papéis normalmente reservado a outros participantes dos canais de distribuição, como atacadistas e distribuidores, gerando uma forma de conflito no canal de distribuição. Todavia, como salientaram os administradores da rede, a presença

REAd | Porto Alegre - Edição 78 - Nº 2 - maio/agosto 2014 - p. 529-570 


\section{Douglas Heinz, Jane Iara Pereira da Costa \& Erick William Pereira}

dos atacadistas e distribuidores nos canais onde há redes de compras continua sendo importante em alguns casos, como em situações de urgência ou pedidos especiais que a rede não consegue atender por algum motivo. Esta situação foi confirmada pelas respostas dos associados, que em sua maioria consideraram os procedimentos de compras adequadas e julgaram conveniente manter relacionamento comercial com atacadistas e distribuidores.

Destaca-se ainda a preocupação com a sobreposição de lojas vinculadas que possam entrar em concorrência direta. Para tanto a aceitação de novos associados depende da aprovação explícita das empresas participantes da rede. Tal sistemática permite ao varejista manter o controle sobre a sua área de influência e foi julgada como adequado (bom ou ótimo) pela maioria dos associados respondentes.

Quadro 7 - Análise comparativa das ações do item distribuição do composto de marketing

\begin{tabular}{|l|l|l|}
\hline \multicolumn{1}{|c|}{ CARACTERÍSTICA } & \multicolumn{1}{|c|}{$\begin{array}{c}\text { AVALIAÇÃO DOS } \\
\text { ADMINISTRADORES }\end{array}$} & AVALIAÇÃO DOS ASSOCIADOS \\
\hline $\begin{array}{l}\text { Existência de centro de } \\
\text { distribuição }\end{array}$ & $\begin{array}{l}\text { O centro de distribuição da rede } \\
\text { executa o papel de um atacadista. }\end{array}$ & $\begin{array}{l}\text { O centro de distribuição foi } \\
\text { considerado muito importante por } \\
92,86 \% \text { dos associados respondentes e } \\
\text { importante por 7,14\%. }\end{array}$ \\
\hline $\begin{array}{l}\text { Entrega de mercadorias } \\
\text { pela rede aos associados }\end{array}$ & $\begin{array}{l}\text { Predomina entrega de mercadorias do } \\
\text { Centro de Distribuição para os } \\
\text { associados através de transporte } \\
\text { terceirizado. Em alguns casos a entrega } \\
\text { é feita pelo fornecedor. }\end{array}$ & $\begin{array}{l}\text { O procedimento foi avaliado como } \\
\text { regular por 7,14\% dos respondentes, } \\
\text { bom por 64,29\% e excelente por } \\
23,08 \%\end{array}$ \\
\hline $\begin{array}{l}\text { Controle da quantidade e } \\
\text { localização dos pontos de } \\
\text { vendas da rede }\end{array}$ & $\begin{array}{l}\text { Adesão de novos associados é } \\
\text { determinada em função de critérios } \\
\text { demográficos. Depende da aprovação } \\
\text { do grupo de associados já participante. }\end{array}$ & $\begin{array}{l}\text { Para 7,69\% dos associados } \\
\text { respondentes, os procedimentos de } \\
\text { definição de áreas de atendimento } \\
\text { exclusivo adotados são regulares, } \\
\text { enquanto 69,23\% consideram bons e } \\
\text { 23,08\% avaliaram como excelentes. }\end{array}$ \\
\hline $\begin{array}{l}\text { Percepção de conflitos nos } \\
\text { canais de distribuição } \\
\text { tradicionais }\end{array}$ & $\begin{array}{l}\text { Rede de compras assume papel } \\
\text { tradicionalmente desempenhado por } \\
\text { atacadistas e distribuidores, causando } \\
\text { conflitos. Em alguns casos os } \\
\text { intermediários são importantes, } \\
\text { principalmente quando há urgência. }\end{array}$ & $\begin{array}{l}\text { Procedimentos de compras foram } \\
\text { considerados adequados por 71,43\% } \\
\text { dos associados. Todavia, um associado } \\
\text { sugeriu considerar compras de } \\
\text { atacadistas quando há condições } \\
\text { vantajosas. }\end{array}$ \\
\hline
\end{tabular}
Fonte: Dados primários (2010)

Finalizando a análise, de modo geral identificou-se que as ações do composto de marketing desenvolvidas pela rede de compras objeto deste estudo seguem algumas premissas: pretende-se obter a redução dos preços de compras com ganhos de escala no volume adquirido, desenvolver comunicação e promoção em conjunto e construir uma estratégia de distribuição que dê suporte às demais ações realizadas através da rede, porém, com o menor impacto possível na autonomia dos associados. 
Composto de marketing em redes de compras: estudo comparativo das percepções de administradores e associados em uma rede de supermercados

\section{CONSIDERAÇÕES FINAIS}

O comércio varejista se encontra em um processo de mudança constante, provocado por um ambiente agressivo que oferece ameaças e oportunidades (KOTLER; ARMSTRONG, 2003). Grandes varejistas têm respondido a este cenário de diferentes maneiras. Alguns lançam novos formatos, enquanto outros buscam baixos custos (GREWAL et al., 2010). Mas no caso de pequenas empresas há dificuldades na adoção de estratégias que permitam competir individualmente neste mercado, pois como não comportam o custo financeiro de um crescimento ágil ou de uma reestruturação, sua atuação pode ficar restrita a nichos de mercado que não são considerados atrativos pelos grandes varejistas (AMARAL, 2007). Para reverter este quadro negativo, as parcerias surgem como alternativa viável para a continuidade do negócio, sendo as redes de compras uma tendência mundial no setor (YEMAL; FUSCO; ROSPI, 2003; GHISI; DE CAMARGO; MARTINELLI, 2003).

As redes de compras são um tipo de arranjo entre organizações que tem como objetivo básico consolidar as necessidades de compras de diversas empresas, aumentando assim o seu poder de negociação junto aos fornecedores. Aparentemente simples, esta proposta ganha complexidade quando colocada em prática, pois mais do que controlar volumes de mercadorias, em uma rede torna-se necessário tomar decisões administrativas que causam impacto coletivo. Considerando o amplo escopo de atividades estudadas pela área de conhecimento da administração de empresas que poderiam ser analisadas em uma rede de compras, este trabalho tratou das características gerais de sua formação e administração, além das ações desenvolvidas em relação ao composto de marketing.

Sendo a rede de compras em questão regida por um acordo formalizado em estatuto, em que uma diretoria composta por associados é eleita com prazos determinados, ela enquadra-se no modelo de redes burocráticas simétricas de Grandori e Soda (1995). Para Amaral (2007, p. 57), “A formalização dos relacionamentos organizacionais nas redes seria marcada por contratos, sempre em construção, o que possibilitariam ajustamentos ao longo do tempo". Na pesquisa realizada esta assertiva é totalmente corroborada pela percepção de administradores e associados sobre o desenvolvimento contínuo da rede de compras, demonstrando que apesar da existência de regras estabelecidas (estatuto), a sociedade entre as empresas está constantemente em discussão visando o aperfeiçoamento das relações pessoais e organizacionais.

Outra consequência da estratégia do associativismo é a implementação gradual de uma padronização nas lojas, no atendimento e no marketing da rede e da imagem dos associados REAd | Porto Alegre - Edição 78 - Nº 2 - maio/agosto 2014 - p. 529-570 
Douglas Heinz, Jane Iara Pereira da Costa \& Erick William Pereira

(Yemal, Fusco e Rospi, 2006). Os itens do composto de marketing são, possivelmente, os elementos mais afetados por este processo, como ficou claro na rede pesquisada, onde constatou-se o desenvolvimento de ações conjuntas relacionadas a produto, preço, promoção e distribuição. Neste sentido, a rede de compras impacta diretamente na administração de marketing de seus associados. Deve-se observar, entretanto, que o princípio de manutenção da independência dos associados, defendido pelos administradores da rede, pressupõe que o aumento das ações conjuntas não deve ser impositivo, mas sim eletivo. Ou seja, aprofundar ou não o grau de integração de uma empresa participante de uma rede com os demais associados continua sendo uma decisão dos empresários que estão à frente de cada organização.

Finalmente, a correlação positiva entre satisfação dos associados e volume de compras através da central de negócios indica que a participação em um arranjo cooperado mostra-se aparentemente positiva para pequenos varejista, confirmando as vantagens desta estratégia. Neste sentido, novos estudos na área podem avançar na comparação das percepções de administradores e associados sobre benefícios e problemas decorrentes da participação em uma rede de compras, em especial nos conflitos horizontais que podem surgir desta relação. Outro ponto que merece ser avaliado é o comportamento dos administradores de redes de compras, que exercem duplo papel na organização, atuando como administradores do grupo ao mesmo tempo em que continuam sendo membros associados.

\section{REFERÊNCIAS}

AMARAL, Jeferson Ney. Competitividade e longevidade de micro e pequenas empresas que atuam ou não em rede: um estudo comparativo de farmácias em Belo Horizonte. Belo Horizonte, 2007, 146 f. Dissertação (Mestrado em Administração). Fundação Mineira de Educação e Cultura.

ARMSTRONG, J. Scott. Evidence-based advertising: An application to persuasion. International Journal of Advertising, v. 30, n. 5, pp. 743-767, 2011

ASSOCIAÇÃO BRASILEIRA DE ATACADISTAS E DISTRIBUIDORES. O setor no Brasil. Disponível em: < http://www.abad.com.br/index2.html>. Acesso em 06 mar. 2010.

ASSOCIAÇÃO BRASILEIRA DE SUPERMERCADOS - ABRAS. Ranking Abras edição 2010. Disponível em <http://www.feiraapas.com.br/uploads/Image/2010_ consolidado_03_ imprensa_04.05.10.pdf> Acesso 11 jan. 2011.

BAILY, Peter et al. Compras: princípios e administração. 8 ed. São Paulo: Atlas, 2000 REAd | Porto Alegre - Edição 78 - No 2 - maio/agosto 2014 - p. 529-570 
Composto de marketing em redes de compras: estudo comparativo das percepções de administradores e associados em uma rede de supermercados

BALESTRIN, A.; VERSCHOORE, J. R.; REYES JUNIOR, E. O campo de estudos sobre redes de cooperação interorganizacional no Brasil. Revista de Administração Contemporânea. v. 14, n. 3, p. 458-477, mai - jun, 2010.

BARBETTA, Pedro Alberto. Estatística aplicada às ciências sociais. 4 ed. Florianópolis: Editora da UFSC, 2001.

BELIK, Walter. Evolução e tendências do varejo. In: MORGADO, M. G.; GONÇALVES, M. N. (org.) Varejo: Administração de empresas comerciais. São Paulo: Editora SENAC São Paulo, 1997.

BERTOLINI, Eni Aparecida S. Gestão do conhecimento: uma aplicação nas atividades operacionais na gestão de redes organizacionais. Revista Técnica IPEP. V. 6, n. 2, p. 21-34, ago/dez, 2006.

BONASSI, Fábio Angelo; LISBOA, Teresinha Covas. O associativismo como estratégia competitiva no varejo: um estudo de caso na Aremac-am - Associação Regional de Empresas de Materiais de Construção da Alta Mogiana. Revista Eletrônica de Administração - Facef Edição 03 V. 2, jul/dez, 2003

BORDEN, N. The concept of Marketing mix. Journal of advertising research, v.1, 9. ed, p. 2-7, 1984.

BRASS, Daniel J. et al. Taking stock of networks and organizations: a multilevel perspective. Academy of Management Journal. v. 47, n. 6, p. 795-817, 2004

CARNEIRO, J. M. T. et al. Formação e administração de preços. 2 ed. Rio de Janeiro: Editora FGV, 2006.

CAVALCANTE, Léia Baeta. Poder de compra do varejo supermercadista: uma abordagem antitruste. Fundaçao Getúlio Vargas, Brasília, 2004, 42 f. Dissertação (MBA em Direito Econômico e das Empresas). Disponível em <https://gestaoseae. fazenda.gov.br/central_documentos/documento_trabalho/2004-1/doctrab30.pdf.> Acesso 26 Abr 2010.

CERVI, R.; RAZZOLINI FILHO, E.; RODRIGUEZ, C. M. T., Centralização de compras como estratégia competitiva: o caso das farmácias magistrais no Paraná. XXIV Encontro nacional de engenharia de produção. Florianópolis, Nov. 2004.

COLLIS, J.; HUSSEY, R. Pesquisa em administração: um guia prático para alunos de graduação e pós-graduação. 2 ed. Porto Alegre: Bookman, 2005. 
Douglas Heinz, Jane Iara Pereira da Costa \& Erick William Pereira

COOPER, Donald R.; SCHINDLER, Pamela S. Métodos de pesquisa em administração. 7 ed. Porto Alegre: Bookman, 2003

DE PÁDUA, Elisabete Machado Marchesini. O trabalho monográfico como iniciação à pesquisa científica. In: DE CARVALHO, Maria Cecília Maringoni (org.). Construíndo o saber: Metodologia científica - fundamentos e técnicas. 2 ed. Campinas: Papirus, 1989.

DOS REIS, Edson Andrade. Análise da viabilidade da formação de uma rede associativa de compras como estratégia competitiva para micro e pequenas indústrias metalmecânicas da região de Jaraguá do Sul (SC). Blumenau, 2009, 103 f. Dissertação (Mestrado em Administração) Universidade Regional de Blumenau.

DUMKE, E.; ANAZCO, J. K.; PAUL, N. Central de negócios: um caminho para a sustentabilidade de seu negócio. Rio de Janeiro: Elsevier, 2010

ESSIG, Michael. Purchasing consortia as symbiotic relationship: developing the concept of “consortium sourcing”. European Journal of Purchasing and Supply Management v. 6, n. 1, p. 13-22, 2000

ETZEL, M. J.; WALKER, B. J.; STANTON, W. J. Marketing. São Paulo: Makron Books, 2001

FIELD, Andy. Descobrindo a estatística usando o SPSS. 2 ed. Porto Alegre: Artmed, 2009

GHISI, F. A.; DE CAMARGO, S. H. C. R. V.; MARTINELLI, D. P. Redes de Compras de Supermercados de Pequeno e Médio Porte: Um estudo multicaso no interior do Estado de São Paulo. Varejo Competitivo, vol. 7. Coordenação: Felisoni de Ângelo, Jose Augusto Gresbrecht da Silveira. São Paulo, Atlas, 2003.

GIGLIO, E. M.; ONUSIC, L. M. Revalorização do modelo de Miles: lições das teorias de redes para decisões estratégicas. REAd - Revista Eletrônica em Administração. ed. 74, n. 1, p. 192-218, janeiro/abril, 2013.

GRANDORI, Anna; SODA, Giuseppe. Inter-firm network: antecedents, mechanisms and forms. Organization studies. v. 16, n. 2, p. 183-214, 1995.

GRESSLER, Lori Alice. Introdução à pesquisa: projetos e relatórios. São Paulo: Edições Loyola, 2003.

GREWAL, Dhruv et. al. Retail Sucess and Key Drivers. In: KRAFFT, M.; MANTRALA M. K. (eds.) Retailing in the $21^{\text {st }}$ Century: current and future trends. 2 ed. Springer, 2010

REAd | Porto Alegre - Edição 78 - Nº 2 - maio/agosto 2014 - p. 529-570 
Composto de marketing em redes de compras: estudo comparativo das percepções de administradores e associados em uma rede de supermercados

GRONROOS, C, Marketing Mix to Relationship Marketing: Towards a Paradigm Shift. Marketing. Management Decision, V. 32, 2.ed 1994

GULATI, Ranjay. Alliances and networks. Strategic Management Journal. v. 19, p. 293317, 1998.

INSTITUTO BRASILEIRO DE GEOGRAFIA E ESTATÍSTICA - IBGE. Pessoal ocupado nas empresas comerciais em 31.12, segundo as divisões, grupos e classes de atividades. Pesquisa Anual do Comércio. v. 20 Disponível em < http://www.ibge.gov.br/home/ estatistica/economia/comercioeservico/pac/2008/tabelas_pdf/parte1_tab8.pdf> . Acesso 27 dez 2010a

INSTITUTO BRASILEIRO DE GEOGRAFIA E ESTATÍSTICA - IBGE. Resultado das empresas comerciais, por divisões de atividade. Pesquisa Anual do Comércio. v. 20 Disponível em <http://www.ibge.gov.br/home/estatistica/economia/ comercioeservico/pac/2008/tabelas_pdf /parte1_tab2.pdf`> . Acesso 27 dez 2010b

JUNG, Carlos Fernando. Metodologia para pesquisa \& desenvolvimento: aplicada a novas tecnologias, produtos e processos. Rio de Janeiro: Axcel Books do Brasil Editora, 2004

KOTLER, P. A Generic Concept of Marketing. Journal of Marketing. v.36, p.46-54, 1972.

KOTLER, Philip. Marketing essencial: conceitos, estratégias e casos. São Paulo: Prentice Hall, 2005

KOTLER, Philip; ARMSTRONG, Gary. Princípios de marketing. 9 ed. São Paulo: Pearson Prentice Hall, 2003.

LAS CASAS, Alexandre Luzzi Administração de marketing: conceitos, planejamento e aplicações à realidade brasileira. São Paulo: Atlas, 2008

LEWIN, A.Y.; LONG, C. P.; CARROLL, T. N.; The coevolution of new organizational forms. Organization Science. v. 10 n. 5, p. 535-550, 1999.

LIMA, Miguel et al. Gestão de marketing. 8 ed. revista e atualizada. Rio de Janeiro: Editora FGV, 2007

LIMA, Patrícia Ennes da Silva. Redes interorganizacionais: uma análise da saída das empresas parceiras. Santa Maria, 2007. Dissertação (Mestrado em Administração). Universidade Federal de Santa Maria. 
Douglas Heinz, Jane Iara Pereira da Costa \& Erick William Pereira

LIVATO, M.; DE BENEDICTO, G. C. Redes de cooperação no varejo: um estudo teóricoempírico em centrais de negócios supermercadistas no estado de São Paulo. Base - Revista de Administração e Contabilidade da Unisinos. v. 13, n. 4, p. 583-603

LUKIANOCENKO, Marlucy. Pesquisa de redes chega à 10a. Edição. Revista SuperHiper. Setembro, 2010. Disponível em < http://www.abrasnet.com.br/economia-epesquisa/pesquisas-sazonais/redes-de-negocios/> Acesso 11 jan. 2011

MARCHI, J. J.; CASSANEGO JUNIOR, P.; WITTMANN, M. L.; Troca e criação de valor: possibilidades competitivas advindas da estratégia de redes. R. Adm. v. 47, n. 2, p. 180-196, abril/maio/junho, 2012

MARDH, P.; CORREIA, T. Marketing mix strategies towards the bottom of the Pyramid: a study of the Brazilian market. Master Thesis. Department of Business Studies. Uppsala Universitet. Spring, 2013. Disponível em <http://www.diva-portal.org/smash/get/ diva2:631828/FULLTEXT01.pdf>. Acesso 16 ago. 2013

MOROSKY, Julio. Centrais de compras: um fenômeno que merece apoio. Disponível em: $<$ http://www.revistaesbrasil.com.br/artigos/82-julio-morosky/337-centrais-de-compra-umfenomeno-que-merece-apoio> Acesso 26 abr 2010.

MOURA, M. L. S.; FERREIRA, M. C. Projetos de pesquisa: elaboração, redação e apresentação. Rio de Janeiro: Eduerj, 2005.

NOHRIA, Nitin. Is a network perspective a useful way of studying orgazanitions? In NOHRIA, N.; ECCCLES, R. G. (eds.). Network and organizations: structure, form and action. Boston: Harvard Business School Press, 1992

OLAVE, Maria Elena León; AMATO NETO, João. Redes de cooperação produtiva: uma estratégia de competitividade e sobrevivência para pequenas e médias empresas. Revista gestão e produção. V. 8, n. 3, p. 289-303, dez., 2001.

OLIVEIRA, A. L.; MACHADO R. T. M. Centrais de compras: um novo agente nos canais de marketing. XI Seminários em Administração. São Paulo, SP, Brasil, 2008

OLIVEIRA, J .F. de. The Influence of the social capital on business performance: an analysis in the context of horizontal business networks. RAM - Rev. Adm. Mackenzie. v. 14, n. 3, ed. especial, p. 209-235, maio/junho, 2013

PEREIRA, José Flávio. Redes de empresas como vantagem competitiva: um estudo de caso sobre as Lojas Móbile. Belo Horizonte (2008). Dissertação (mestrado). Faculdade Novos Horizontes. 
Composto de marketing em redes de compras: estudo comparativo das percepções de administradores e associados em uma rede de supermercados

PEREIRA, E. W.. Análise da relação entre cenários temáticos de restaurantes e a satisfação do consumidor. 2011. 99f. Dissertação (Mestrado em Administração) Universidade do Vale do Itajaí - UNIVALI, Biguaçu, 2011.

POUSA, Rogério et al. Os ciclos de vida das centrais de negócios: um estudo no setor supermercadista no Estado de São Paulo. XIII SIMPEP - Simpósio de engenharia de produção. Bauru/SP, 06 a 08 Novembro, 2006.

PRIDE, W. M.; FERRELL, O.C. Marketing: conceitos e estratégias. 11 ed. Rio de Janeiro: LTC, 2001.

PROVAN, K. G.; FISH, A.; SYDOW, J. Interorganizational networks at the network level: a review of the empirical literature on whole networks. Journal of Management, v. 33, 2007

REA, Louis M.; PARKER, Richard A. Metodologia da Pesquisa: do planejamento à execução. São Paulo: Pioneira, 2000.

RETSEPTOR, Gennady. 40 Inventive Principles in Marketing, Sales and Advertisin, Triz Journal, 2005, 4.ed.

RICHARDSON, Roberto Jarry. Pesquisa Social: métodos e técnicas. 3 ed. São Paulo: Atlas, 1999.

ROLO, Teresa Maria de Oliveira. Contributo para a análise dos factores críticos de sucesso para a dinamização da cooperação inter empresarial. Lisboa (2001). Dissertação (mestrado). Universidade Técnica de Lisboa.

ROTH, Ana Lúcia et al. Diferenças e inter-relações dos conceitos de governança e gestão de redes horizontais de empresas: contribuições para o campo de estudo. R. Adm. v. 47, n. 1, p. 112-123, janeiro/fevereiro/março, 2012

SAAB, W. G. L.; GIMENEZ, L. C. P.; RIBEIRO, R. M. Supermercados no Brasil: o movimento das empresas menores. BNDES Setorial, n. 24, dez., 2000. Disponível em < http://www.bndes.gov.br/SiteBNDES/export/sites/default/bndes_pt/Galerias/Arquivos/conhec imento/setorial/get4is24.pdf> . Acesso 30 jul. 2010.

SANTOS, Gilmar. Princípios da Publicidade. Belo Horizonte: Editora UFMG, 2005. 
Douglas Heinz, Jane Iara Pereira da Costa \& Erick William Pereira

SOARES, Ari de Souza et al. Benefícios competitivos e conflitos em rede horizontal do setor supermercadista. REAd - Revista Eletrônica em Administração. ed. 69, v. 17, n. 2, maio/agosto, 2011

TEIXEIRA; A. K. G; BARBOSA, M. L. A. O sistema de oferta de restaurantes de alta gastronomia: uma perspectiva sensorial das experiências de consumo. In: ENANPAD ENCONTRO ANUAL DOS PROGRAMAS DE PÓS-GRADUAÇÃO EM ADMINISTRAÇÃO. 23.ed, 2008, Rio de Janeiro. Anais... Rio de Janeiro: ANPAD, 2008.

URDAN, Flávio Torres; URDAN, André Torres. Gestão do composto de marketing. São Paulo: Atlas, 2006

VAN WATERSCHOOT, W.; VAN DEN BULTE, C. The 4P classification oh the marketing mix revisited. Journal of Marketing, v. 56, p. 83-93, 1992

VAROTTO, Luís Fernando. História do Varejo. RAE - Revista de Administração de Empresas. Vol. 5, n. 1, fev/abr, 2006. Disponível em: < http://www16.fgv.br/rae/artigos /4224.pdf>. acesso 10 jan. 2011

WEGNER, Douglas; PADULA, Antônio D. Governance and management of horizontal business networks: an analysis of retail networks in Germany. International Journal of Business and Management. v. 5, n. 12, 2010.

XAVIER FILHO, J. L. J. et al. Proposta para a avaliação da contribuição de centrais de negócios para a empresa participante: o caso da central de negócio "Rede Âncora de Autopeças”. Revista de Negócios. v. 15, n. 4, p. 113-136

YEMAL, J. A.; FUSCO, J. P. A.; ROSPI, L. Formação de alianças estratégicas no setor supermercadista. XIII SIMPEP - Simpósio de engenharia de produção. Bauru/SP, 06 a 08 Novembro, 2006.

YIN, R. K. Estudo de Caso: planejamento e métodos. 3a ed. Porto Alegre: Bookman, 2005.

ZEITHAML, V. A; BITNER. M. J. Services Marketing. New York: McGraw Hill, 1996. 
Composto de marketing em redes de compras: estudo comparativo das percepções de administradores e associados em uma rede de supermercados

\section{APÊNDICE 1: Roteiro de entrevista com Administradores da Rede de Compras}

\section{BLOCO 1: APRESENTAÇÃO DA REDE}

1.1 DADOS GERAIS
a) Nome
b) Data de fundação
c) Número de associados (atual e evolução)
d) Quantidade, tipo e propriedade (próprio, alugado) das instalações da rede
e) Área de abrangência dos associados

\subsection{ORGANIZAÇÃO SOCIETÁRIA E ADMINSTRAÇÃO DA REDE}
a) Como surgiu a rede?
b) Qual a estrutura societária da rede?
c) Como é o processo de gestão e tomada de decisão da rede?
d) Quais as principais dificuldades deste processo de gestão?
e) Quais são os critérios para aceitação/seleção de novos sócios na rede?
f) Há algum tipo de controle de desempenho dos participantes? Caso positivo,qQuais? Se não, por quê?
g) Os associados recolhem algum tipo de taxa/anuidade?

\section{BLOCO 2: PROCESSO COMERCIAL}

\subsection{COMPRAS}

a) Qual o procedimento de compras da rede? 
Douglas Heinz, Jane Iara Pereira da Costa \& Erick William Pereira

b) Como os associados apresentam suas necessidades para a rede? Que meios de comunicação eles utilizam?

c) Os associados têm autonomia para realizar compras independentes da rede?

d) Como é feito o pagamento das compras? Os associados pagam para a rede ou direto para os fornecedores?

e) Como é o processo de negociação com os fornecedores?

f) Qual é o procedimento fiscal envolvido no repasse dos produtos aos associados?

\section{BLOCO 3: MIX DE MARKETING}

\section{$3.1 \quad$ PRODUTO}

a) Quais as linhas/produtos e marcas comercializados pela rede?

b) Os associados participam da definição da linha de produtos?

c) Os associados têm autonomia para trabalhar com produtos e/ou oferecer serviços que não estejam vinculados àqueles definidos pela rede de compras?

d) A rede possui marca própria? Se negativo, pensa desenvolvê-la? Se positivo, como surgiu? Que produtos abrange? Pensa em expandir?

e) A rede oferece algum serviço adicional aos produtos oferecidos?

f) A rede possui políticas específicas para serviços, como entrega e troca de mercadoria?

\subsection{PREÇOS}

a) Os descontos obtidos dos fornecedores em relação a uma compra “individual” são repassados integralmente para os associados? Estes descontos são vantajosos?

b) A rede interfere na definição de preços ou oferecimento de descontos pelos associados? Se positivo, faz por imposição ou por sugestão? Se negativo, não teme prejuízos à sua imagem?

c) A rede interfere em questões como a forma de pagamento e o sistema de crediário oferecido pelos associados? Se positivo, faz por imposição ou por sugestão? Se negativo, não teme prejuízos à sua imagem? 
Composto de marketing em redes de compras: estudo comparativo das percepções de administradores e associados em uma rede de supermercados

\subsection{COMUNICAÇÃO}

a) A rede possui um sistema de comunicação integrado para todos os associados? Se positivo, o que ele compreende (promoções, identificação visual, propaganda, merchandising, etc...) e como é definido?

b) Como as promoções são definidas? Como a rede troca informações com os associados a este respeito?

c) Como é definido o orçamento para estas promoções? Como os recursos são obtidos?

d) As promoções da rede são voltadas apenas ao consumidor final ou também há promoções voltadas aos varejistas?

e) Os associados podem realizar promoções por iniciativa própria?

\subsection{DISTRIBUIÇÃO}

a) Qual o procedimento de recebimento e distribuição dos produtos para os associados?

b) O transporte é próprio ou terceirizado? O que justifica esta opção?

c) A empresa negocia com atacadistas e distribuidores ou exclusivamente com fabricantes?

d) Como são definidas as regiões atendidas pela rede e os associados em cada local? Há restrições quanto ao número de associados em uma região?

\section{BLOCO 4: CARACTERÍSTICAS DA REDE}

a) Qual é o comportamento esperado dos sócios em relação à rede?

b) Como avalia o relacionamento dos associados com a rede? Apresentam muitas críticas e sugestões? São aproveitadas, como?

c) Qual a importância da rede para os associados? Quais benefícios ela gera?

d) Quais os principais problemas/dificuldades relatados pelos associados?

e) A rede desenvolve outras atividades além daquelas relacionadas à questões comerciais (por exemplo, responsabilidade sócio-ambiental)?

Obs: Pesquisar antecipadamente os dados do item 1.1 e apenas confirmar com o entrevistado. 
Douglas Heinz, Jane Iara Pereira da Costa \& Erick William Pereira

APÊNDICE 2: Questionário aplicado aos Associados da Rede de Compras

\begin{tabular}{|l|l|}
\hline Empresa & \\
\hline Filiada a rede & \\
\hline $\begin{array}{l}\text { Nome do responsável pelas } \\
\text { respostas }\end{array}$ & \\
\hline
\end{tabular}

\section{BLOCO 1 - A REDE, A EMPRESA E O PROCESSO DE COMPRAS}

Há quanto tempo a sua empresa é filiada à rede?

Resposta:

Quantas unidades (matriz + filiais) a sua empresa possui?

\begin{tabular}{|l|l|}
\hline & Uma \\
\hline & Duas \\
\hline & Três \\
\hline & Quatro \\
\hline & Mais de quatro \\
\hline
\end{tabular}

Considerando o volume financeiro, qual o percentual aproximado das compras da sua empresa feitas através da rede?

\begin{tabular}{|l|l|}
\hline & Até $20 \%$ \\
\hline & Entre $21 \%$ e $40 \%$ \\
\hline & Entre $41 \%$ e $60 \%$ \\
\hline & Entre $61 \%$ e $80 \%$ \\
\hline & Mais de $80 \%$ \\
\hline
\end{tabular}

Sobre os itens abaixo, indique os 3 (três) principais motivos para a participação da sua empresa na rede.

\begin{tabular}{|l|l|}
\hline Número & Item \\
\hline
\end{tabular}

REAd | Porto Alegre - Edição 78 - Nº 2 - maio/agosto 2014 - p. 529-570 
Composto de marketing em redes de compras: estudo comparativo das percepções de administradores e associados em uma rede de supermercados

\begin{tabular}{|l|l|}
\hline & Redução dos preços de compras \\
\hline & Rateios nas despesas \\
\hline & Reconhecimento da marca \\
\hline & Melhorias na logística \\
\hline & Aprimoramento da estratégia de negócios \\
\hline & Aumento da competitividade \\
\hline & Melhorias nos serviços oferecidos aos clientes \\
\hline & Especialização do comprador \\
\hline & Acesso a fornecedores \\
\hline & Maior poder de negociação \\
\hline & Outro. Especificar: \\
\hline & Outro. Especificar: \\
\hline
\end{tabular}

Sobre os itens abaixo, indique os 3 (três) principais problemas que a empresa encontra na sua participação na rede.

\begin{tabular}{|l|l|}
\hline Número & Item \\
\hline & Constituição societária da rede \\
\hline & Informações não são repassadas de forma igual aos associados \\
\hline & Diferença de tamanho entre os associados da rede \\
\hline & Processo de gestão e tomada de decisão \\
\hline & Custo-benefício \\
\hline & Conflito entre os interesses da rede e da empresa \\
\hline & Outro. Especificar: \\
\hline & Outro. Especificar: \\
\hline
\end{tabular}

\begin{tabular}{|l|l|c|c|c|c|c|}
\hline $\begin{array}{l}\text { Avalie os seguintes aspectos } \\
\text { da rede de compras }\end{array}$ & $\begin{array}{c}\mathbf{1} \\
\text { Péssimo }\end{array}$ & $\begin{array}{c}\mathbf{2} \\
\text { Ruim }\end{array}$ & $\begin{array}{c}\mathbf{3} \\
\text { Regular }\end{array}$ & $\begin{array}{c}\mathbf{4} \\
\text { Bom }\end{array}$ & $\begin{array}{c}\mathbf{5} \\
\text { Excelente }\end{array}$ & $\begin{array}{c}\text { Sem } \\
\text { opinião }\end{array}$ \\
\hline $\begin{array}{l}\text { Critérios para seleção e } \\
\text { aceitação de novos } \\
\text { associados }\end{array}$ & & & & & \\
\hline $\begin{array}{l}\text { Processo de gestão e tomada } \\
\text { de decisão da rede }\end{array}$ & & & & & & \\
\hline $\begin{array}{l}\text { Controles aplicados pela } \\
\text { rede aos associados }\end{array}$ & & & & & & \\
\hline $\begin{array}{l}\text { Procedimentos de compras } \\
\text { Formas de pagamento das } \\
\text { compras do associado para } \\
\text { a rede }\end{array}$ & & & & & & \\
\hline $\begin{array}{l}\text { Procedimento fiscal e } \\
\text { tributário para o repasse } \\
\text { dos produtos aos associados }\end{array}$ & & & & & & \\
\hline $\begin{array}{l}\text { Treinamentos oferecidos aos } \\
\text { associados }\end{array}$ & & & & & \\
\hline
\end{tabular}

REAd | Porto Alegre - Edição 78 - N 2 - maio/agosto 2014 - p. 529-570 
Douglas Heinz, Jane Iara Pereira da Costa \& Erick William Pereira

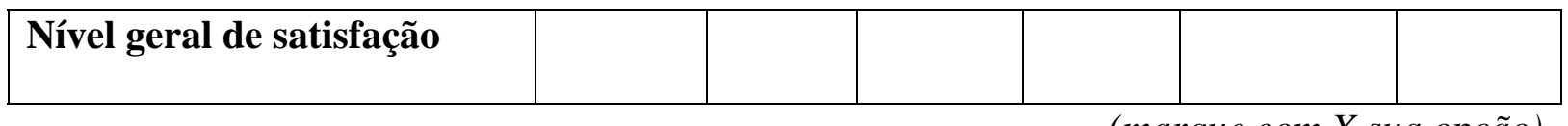

(marque com $X$ sua opção)

\section{BLOCO 2 - PRODUTO}

\begin{tabular}{|l|l|l|l|l|l|}
\hline & $\begin{array}{c}\text { Diminui } \\
\text { muito }\end{array}$ & $\begin{array}{c}\text { Diminuiu } \\
\text { pouco }\end{array}$ & $\begin{array}{c}\text { Permaneceu } \\
\text { igual }\end{array}$ & $\begin{array}{c}\text { Aumentou } \\
\text { pouco }\end{array}$ & $\begin{array}{c}\text { Aumentou } \\
\text { muito }\end{array}$ \\
\hline $\begin{array}{l}\text { Após associar-se a rede, a } \\
\text { variedade de Produtos } \\
\text { oferecidos por sua empresa: }\end{array}$ & & & & & \\
\hline $\begin{array}{l}\text { Após associar-se a rede, a } \\
\text { variedade de Marcas } \\
\text { oferecidas por sua empresa: }\end{array}$ & & & & & \\
\hline
\end{tabular}

\begin{tabular}{|l|l|l|l|l|l|}
\hline & $\begin{array}{c}\text { Nada } \\
\text { importante }\end{array}$ & $\begin{array}{c}\text { Pouco } \\
\text { importante }\end{array}$ & Indiferente & Importante & $\begin{array}{c}\text { Muito } \\
\text { importante }\end{array}$ \\
\hline $\begin{array}{l}\text { Para a sua empresa, a } \\
\text { padronização dos } \\
\text { serviços (ex. entrega), } \\
\text { oferecidos por todos os } \\
\text { associados da rede aos } \\
\text { clientes é: }\end{array}$ & & & & \\
\hline $\begin{array}{l}\text { Para a sua empresa, a } \\
\text { utilização de uma marca } \\
\text { própria de produtos da }\end{array}$ & & & & \\
rede é: & & & & \\
\hline
\end{tabular}

Para a sua empresa, a rede deveria ter alguma outra política sobre a linha de produtos comercializada?

\begin{tabular}{|l|l|}
\hline Não \\
\hline & Sim. Qual(is)? \\
\hline & \\
\hline
\end{tabular}


Composto de marketing em redes de compras: estudo comparativo das percepções de administradores e associados em uma rede de supermercados

Para a sua empresa, a rede deveria ter alguma outra política sobre as marcas comercializadas?

\begin{tabular}{|l|l|}
\hline & Não \\
\hline Sim. Qual(is)? \\
\hline \\
\hline
\end{tabular}

\section{BLOCO 3 - PREÇOS}

\begin{tabular}{|l|l|l|l|l|l|}
\hline & $\begin{array}{c}\text { Nada } \\
\text { importante }\end{array}$ & $\begin{array}{c}\text { Pouco } \\
\text { importante }\end{array}$ & Indiferente & Importante & $\begin{array}{c}\text { Muito } \\
\text { importante }\end{array}$ \\
\hline $\begin{array}{l}\text { Qual a importância que a } \\
\text { empresa atribui a uma } \\
\text { eventual padronização } \\
\text { das dormas de } \\
\text { pagamento oferecidas } \\
\text { aos clientes por todos os } \\
\text { associados da rede: }\end{array}$ & & & & \\
\hline $\begin{array}{l}\text { Qual a importância que a } \\
\text { empresa atribui a uma } \\
\text { eventual padronização } \\
\text { dos descontos oferecidos } \\
\text { aos clientes por todos os } \\
\text { associados da rede é: }\end{array}$ & & & & \\
\end{tabular}

\begin{tabular}{|l|l|l|l|l|l|}
\hline & $\begin{array}{c}\text { Muito } \\
\text { menores }\end{array}$ & $\begin{array}{c}\text { Um pouco } \\
\text { menores }\end{array}$ & Iguais & $\begin{array}{c}\text { Um pouco } \\
\text { maiores }\end{array}$ & $\begin{array}{c}\text { Muito } \\
\text { Maiores }\end{array}$ \\
\hline $\begin{array}{l}\text { Após a associação à rede, } \\
\text { os precos que a sua } \\
\text { empresa passou a a } \\
\text { oferecer aos clientes } \\
\text { relação aos concorrentes } \\
\text { são: }\end{array}$ & & & & & \\
\hline Como os clientes & & & & & \\
\hline
\end{tabular}

REAd | Porto Alegre - Edição 78 - N 2 - maio/agosto 2014 - p. 529-570 
Douglas Heinz, Jane Iara Pereira da Costa \& Erick William Pereira

\begin{tabular}{|l|l|l|l|l|}
\hline $\begin{array}{l}\text { percebem os preços dos } \\
\text { produtos da sua empresa } \\
\text { em relação aos } \\
\text { concorrentes: }\end{array}$ & & & \\
\hline $\begin{array}{l}\text { Em relação a uma } \\
\text { compra feita diretamente } \\
\text { ao fornecedor, os preços } \\
\text { obtidos através da rede } \\
\text { podem ser considerados: }\end{array}$ & & & \\
\hline $\begin{array}{l}\text { Em relação a uma } \\
\text { compra feita diretamente }\end{array}$ & & & \\
$\begin{array}{l}\text { ao fornecedor, as } \\
\text { condiç̃es de pagamento }\end{array}$ & & & \\
\hline $\begin{array}{l}\text { obtidas através da rede } \\
\text { podem ser consideradas: }\end{array}$ & & & \\
\hline
\end{tabular}

Para a sua empresa, a rede deveria ter alguma outra política sobre precos?

\begin{tabular}{|l|l|}
\hline & Não \\
\hline Sim. Qual(is)? \\
\hline \\
\hline \\
\hline
\end{tabular}

Para a sua empresa, a rede deveria ter alguma outra política sobre formas de pagamento?

\begin{tabular}{|l|l|}
\hline & Não \\
\hline Sim. Qual(is)? \\
\hline \\
\hline \\
\hline
\end{tabular}

\section{BLOCO 4 - COMUNICAÇÃO}

Avalie os seguintes aspectos da comunicação da rede de compras com os clientes:

\begin{tabular}{|l|c|c|c|c|c|c|}
\hline Item & $\mathbf{1}$ & $\mathbf{2}$ & $\mathbf{3}$ & $\mathbf{4}$ & $\mathbf{5}$ & $\begin{array}{c}\text { Sem } \\
\text { opinião }\end{array}$ \\
\hline
\end{tabular}

REAd | Porto Alegre - Edição 78 - № 2 - maio/agosto 2014 - p. 529-570 
Composto de marketing em redes de compras: estudo comparativo das percepções de administradores e associados em uma rede de supermercados

\begin{tabular}{|l|l|l|l|l|l|l|}
\hline Folhetos de oferta & & & & & & \\
\hline Outdoor & & & & & & \\
\hline Rádio & & & & & & \\
\hline Televisão & & & & & & \\
\hline Jornais & & & & & & \\
\hline Revistas & & & & & & \\
\hline Internet & & & & & & \\
\hline Outros (informar): & & & & & & \\
\hline
\end{tabular}

Avalie as seguintes promoções feitas em pela rede

\begin{tabular}{|l|c|c|c|c|c|c|}
\hline Item & $\mathbf{1}$ & $\mathbf{2}$ & $\mathbf{3}$ & $\mathbf{4}$ & $\mathbf{5}$ & $\begin{array}{c}\text { Sem } \\
\text { Péssimo }\end{array}$ \\
Ruim & $\begin{array}{c}\text { Regular } \\
\text { Sorteios }\end{array}$ & & & & & \\
\hline Outros (informar): & & & & & & \\
\hline & & & & & & \\
\hline
\end{tabular}

Avalie

\begin{tabular}{|l|c|c|c|c|c|c|}
\hline Item & $\begin{array}{c}\mathbf{1} \\
\text { Péssimo }\end{array}$ & $\begin{array}{c}\mathbf{2} \\
\text { Ruim }\end{array}$ & $\begin{array}{c}\mathbf{3} \\
\text { Regular }\end{array}$ & $\begin{array}{c}\mathbf{4} \\
\text { Bom }\end{array}$ & $\begin{array}{c}\mathbf{5} \\
\text { Excelente }\end{array}$ & $\begin{array}{c}\text { Sem } \\
\text { opinião }\end{array}$ \\
\hline $\begin{array}{l}\text { O nome da marca da } \\
\text { rede }\end{array}$ & & & & & & \\
\hline $\begin{array}{l}\text { A comunicação entre a } \\
\text { rede e os associados }\end{array}$ & & & & & & \\
\hline $\begin{array}{l}\text { A comunicação entre os } \\
\text { associados da rede }\end{array}$ & & & & & & \\
\hline
\end{tabular}

A sua empresa realiza propaganda por conta própria?

\begin{tabular}{|l|l|}
\hline & Não, apenas as propagandas feitas através da rede. \\
\hline & Sim, poucas vezes \\
\hline & Sim, na maioria das vezes \\
\hline
\end{tabular}

Para a empresa, a rede deveria ter alguma outra política sobre comunicacão?

\begin{tabular}{|l|l|}
\hline & Não \\
\hline & \\
\hline
\end{tabular}

REAd | Porto Alegre - Edição 78 - № 2 - maio/agosto 2014 - p. 529-570 
Douglas Heinz, Jane Iara Pereira da Costa \& Erick William Pereira

\begin{tabular}{|l|l|}
\hline Sim. Qual(is)? \\
\hline \\
\\
\end{tabular}

Para a empresa, a rede deveria ter alguma outra política sobre propaganda?

\begin{tabular}{|l|l|}
\hline & Não \\
\hline & \\
\hline & \\
\hline BLOCO 5 - DISTRIBUIÇÃO \\
\hline
\end{tabular}

Qual forma a sua empresa mais utiliza para receber produtos comprados pela rede:

\begin{tabular}{|l|l|}
\hline & A empresa retira os produtos no armazém da rede com veículo próprio \\
\hline & A empresa retira os produtos no armazém da rede com veículo terceirizado \\
\hline & A rede entrega os produtos na empresa com veículos terceirizados \\
\hline & Os fornecedores entregam os produtos diretamente na empresa \\
\hline
\end{tabular}

Como a sua empresa avalia este processo de entrega dos produtos na empresa?

\begin{tabular}{|l|l|}
\hline & Péssimo \\
\hline & Ruim \\
\hline & Regular \\
\hline & Bom \\
\hline & Excelente \\
\hline & Sem opinião \\
\hline
\end{tabular}

Como a sua empresa avalia a política da rede para definir as áreas de atendimento exclusivo de cada associado?

\begin{tabular}{|l|l|}
\hline & Péssimo \\
\hline & Ruim \\
\hline & Regular \\
\hline & Bom \\
\hline & Excelente \\
\hline & Sem opinião \\
\hline
\end{tabular}

A sua empresa oferece serviço de entrega aos seus clientes?

\begin{tabular}{|l|l|}
\hline & Não e nem pretende oferecer \\
\hline & Não, mas pretende oferecer \\
\hline & Sim, com veículo terceirizado \\
\hline
\end{tabular}

REAd | Porto Alegre - Edição 78 - Nº 2 - maio/agosto 2014 - p. 529-570 
Composto de marketing em redes de compras: estudo comparativo das percepções de administradores e associados em uma rede de supermercados

Sim, com veículo próprio

Para a sua empresa, a existência de um centro de distribuição da rede é:

\begin{tabular}{|l|l|}
\hline & Nada importante \\
\hline & Pouco importante \\
\hline & Indiferente \\
\hline & Importante \\
\hline & Muito importante \\
\hline
\end{tabular}

Para a sua empresa, a rede deveria ter alguma outra política sobre distribuição?

\begin{tabular}{|l|l|}
\hline & Não \\
\hline & Sim. Qual(is)? \\
\hline & \\
\hline
\end{tabular}

Muito obrigado 